Pacific Northwest

National Laboratory

Operated by Battelle for the

U.S. Department of Energy

\section{Recent Site-Wide Transport Modeling Related to the Carbon Tetrachloride Plume at the Hanford Site}

\author{
M. P. Bergeron \\ C. R. Cole
}

October 2005

Prepared for the U.S. Department of Energy under Contract DE-AC05-76RL01830 


\title{
DISCLAIMER
}

This report was prepared as an account of work sponsored by an agency of the United States Government. Neither the United States Government nor any agency thereof, nor Battelle Memorial Institute, nor any of their employees, makes any warranty, express or implied, or assumes any legal liability or responsibility for the accuracy, completeness, or usefulness of any information, apparatus, product, or process disclosed, or represents that its use would not infringe privately owned rights. Reference herein to any specific commercial product, process, or service by trade name, trademark, manufacturer, or otherwise does not necessarily constitute or imply its endorsement, recommendation, or favoring by the United States Government or any agency thereof, or Battelle Memorial Institute. The views and opinions of authors expressed herein do not necessarily state or reflect those of the United States Government or any agency thereof.

\author{
PACIFIC NORTHWEST NATIONAL LABORATORY \\ operated by \\ BATTELLE \\ for the \\ UNITED STATES DEPARTMENT OF ENERGY \\ under Contract DE-AC05-76RL01830 \\ Printed in the United States of America \\ Available to DOE and DOE contractors from the \\ Office of Scientific and Technical Information, \\ P.O. Box 62, Oak Ridge, TN 37831-0062; \\ ph: (865) 576-8401 \\ fax: (865) 576-5728 \\ email: reports@adonis.osti.gov
}

Available to the public from the National Technical Information Service, U.S. Department of Commerce, 5285 Port Royal Rd., Springfield, VA 22161 ph: (800) 553-6847

fax: (703) 605-6900

email: orders@ntis.fedworld.gov

online ordering: http://www.ntis.gov/ordering.htm

This document was printed on recycled paper.

$(9 / 2004)$ 


\title{
Recent Site-Wide Transport Modeling Related to the Carbon Tetrachloride Plume at the Hanford Site
}

\author{
M. P. Bergeron \\ C. R. Cole
}

October 2005

\author{
Prepared for \\ the U.S. Department of Energy \\ under Contract DE-AC05-76RL01830 \\ Pacific Northwest National Laboratory \\ Richland, Washington 99352
}




\section{Executive Summary}

The Hanford Carbon Tetrachloride Innovative Treatment Remediation Demonstration (ITRD) Program provided an initial evaluation of the nature and extent of carbon tetrachloride contamination in the unconfined aquifer in the 200 West Area of the Hanford Site. After the ITRD program ended, subsequent studies more closely examined the transport of carbon tetrachloride (CC14) in the unconfined aquifer system. Those studies were undertaken to support strategic planning and provide guidance for the more robust modeling needed to obtain a final record of decision (ROD) for the carbon tetrachloride plume. This report documents the technical approach and results of those studies.

The ITRD modeling study examined carbon tetrachloride concentrations at an arbitrary boundary between the 200 East and 200 West Areas. After that work was completed, questions arose concerning the concentrations reaching the Columbia River as well as about the impact of remediation options involving source removal or absence. To address those questions, additional modeling studies were conducted using the site-wide groundwater model (SGM) with the modeling domain extended to the Columbia River. This modeling analysis resulted in the following conclusions:

With the assumption of a continuing source with no sorption or abiotic degradation (Case 1a), we observed:

- Development and migration of a substantial carbon tetrachloride plume from source areas in the 200 West Area to the Columbia River. Predicted concentrations reached about $200 \mu \mathrm{g} / \mathrm{L}$ at the arbitrary boundary chosen for this analysis and about $34 \mu \mathrm{g} / \mathrm{L}$ along the Columbia River during the 1000-year period of analysis. Both of these values exceed the benchmark maximum concentration limit (MCL) of $5 \mu \mathrm{g} / \mathrm{L}$

- The equilibrium carbon tetrachloride release estimate in the source area was about $73 \mathrm{~kg} / \mathrm{yr}$.

- Initial conditions yielded an initial mass of about $542 \mathrm{~kg}$ in the aquifer, which grew to $58,050 \mathrm{~kg}$ after 1000 years (the year 3000).

With the assumption of a continuing source with median value estimates of sorption and abiotic degradation (Case 1b), we observed:

- Limited development and migration of a carbon tetrachloride plume from source areas within the general vicinity of the 200 West Area. Predicted concentrations reached about $4.5 \mu \mathrm{g} / \mathrm{L}$ at the arbitrary boundary chosen for this analysis. Concentrations at discharge areas along the Columbia River did not reach any substantial levels during the 1000-year period of analysis.

- The combination of sorption and abiotic degradation rate significantly limits aquifer source loading and the aquifer area and volume affected by the carbon tetrachloride plume migration. The more important parameter of the two is the abiotic degradation rate because retardation alone will not reduce concentrations other than through dilution because of hydrodynamic dispersivity.

Without a continuing source of carbon tetrachloride and no sorption or abiotic degradation, we observed results that were very similar whether the source area with the highest concentrations in the 
plume (i.e., above $3000 \mu \mathrm{g} / \mathrm{L}$ ) was assumed to be removed from the aquifer (Case 2) or the existing plume was considered an initial condition of aquifer contamination (Case 3). In both cases we observed:

- A more limited development and migration of a carbon tetrachloride plume outside the 200 West Area toward the Columbia River than with the continuing source assumption evaluated in Case 1a.

- A predicted concentration profile reaching about $6.5 \mu \mathrm{g} / \mathrm{L}$ at the arbitrary boundary over a period of about 600 years between 2100 and 2700. This contrasts with the rapidly rising and plateauing profile of carbon tetrachloride concentrations predicted under the continuing source assumption evaluated in Case 1a.

- A concentration profile at discharge areas along the Columbia River that is well below the benchmark MCL level of $5 \mu \mathrm{g} / \mathrm{L}$ during the 1000-year period of analysis.

In summary, the results of these analyses illustrate the importance of developing field-scale estimates of $\mathrm{K}_{\mathrm{d}}$ and $\mathrm{K}_{\mathrm{a}}$ for carbon tetrachloride. With $\mathrm{K}_{\mathrm{d}}$ and $\mathrm{K}_{\mathrm{a}}$ of zero, carbon tetrachloride concentrations will exceed the compliance limit of $5 \mu \mathrm{g} / \mathrm{L}$ outside the 200 Area Plateau waste management area, and the aquifer source loading and area of the aquifer affected will continue to grow until river arrival rates equal source release rates of an estimated $73 \mathrm{~kg} / \mathrm{yr}$. Results of this modeling analysis show that natural attenuation parameters $\mathrm{K}_{d}$ and $\mathrm{K}_{\mathrm{a}}$ are critical (especially $\mathrm{K}_{\mathrm{a}}$ ) in predicting the future movement of carbon tetrachloride from the 200 West Area. Results also show the significant change in predictions between continual source release from the vadose zone and complete source removal. 


\section{Contents}

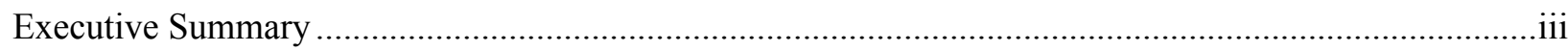

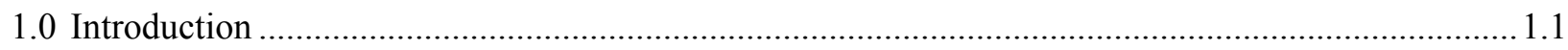

1.1 Overview of the Hanford Carbon Tetrachloride Plume .............................................................. 1.1

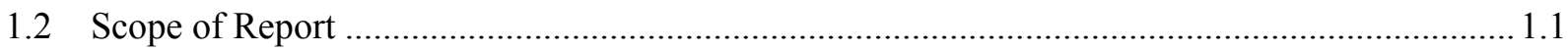

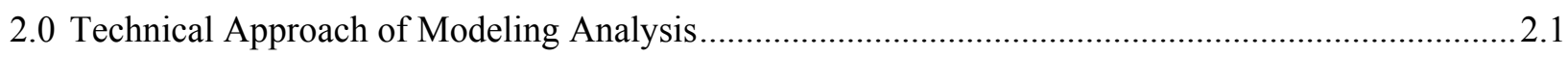

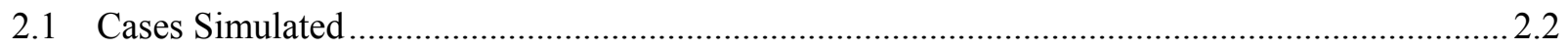

2.2 Initial Conditions - Three-Dimensional Interpretation of Plume ............................................ 2.2

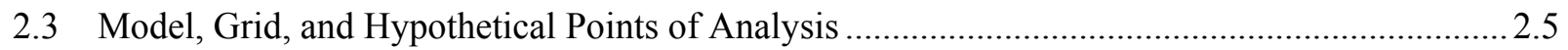

2.4 Natural Attenuation Modeling Parameters .......................................................................... 2.6

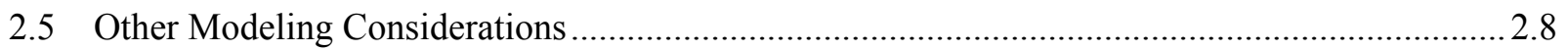

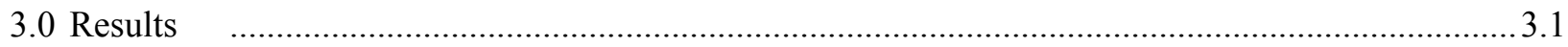

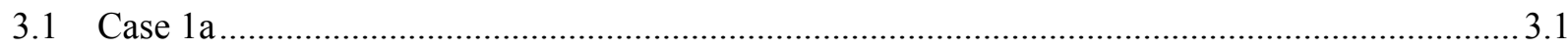

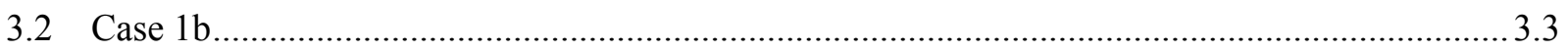

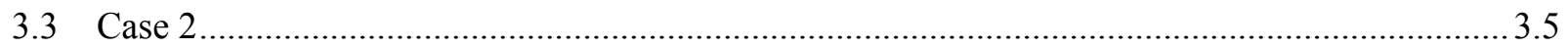

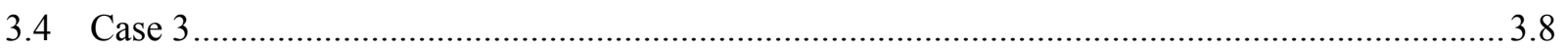

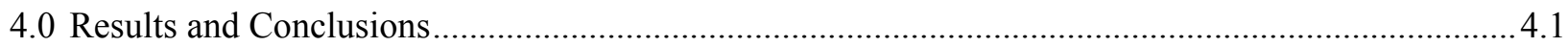

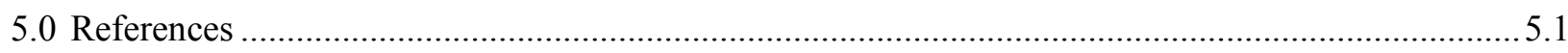

Appendix: Predicted Distributions of Carbon Tetrachloride Derived from Modeling Studies

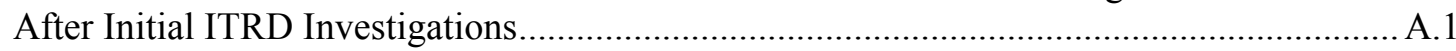




\section{Figures}

2.1 SGM Model Grid of 200 East and West Areas ......................................................................2.1

2.2 Map of Carbon Tetrachloride Concentration Data Used in Geostatistical Analysis. .....................2.3

2.3 Block Diagrams Showing Median of First 100 Geostatistical Simulations of 3-D Carbon

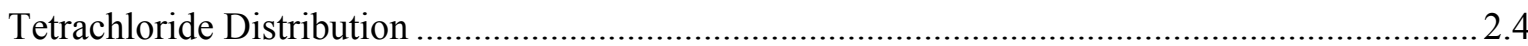

2.4 Vertical Summation of Simulated Median Carbon Tetrachloride Concentration and Proportion Within Three Source Blocks to Total Summed Concentration .................................... 2.5

2.5 Initial Conditions for Current and Previous ITRD Modeling .....................................................2.6

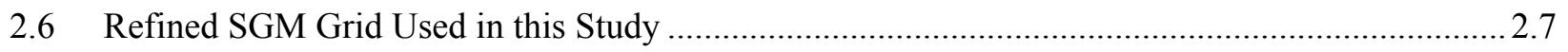

2.7 Histograms of 1000 Simulated Values of Each of the Four Input Parameters Used in

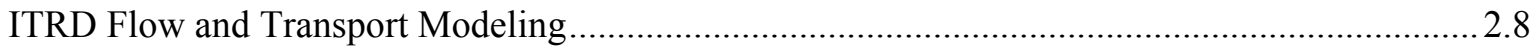

3.1 Carbon Tetrachloride Concentrations at ITRD Study Compliance Boundary and Along Columbia River for Case 1a ................................................................................................... 3.1

3.2 Aquifer Areas Above Specified Concentration Levels for Case 1a ............................................ 3.2

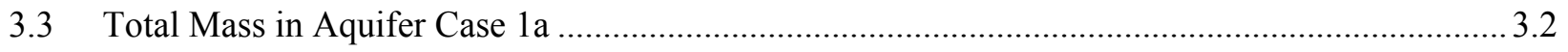

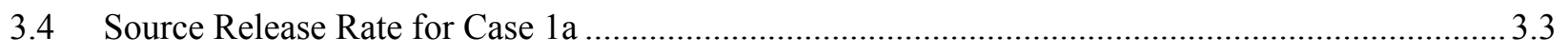

3.5 Carbon Tetrachloride Concentration at ITRD Study Compliance Boundary for Case 1b................. 3.4

3.6 Aquifer Areas Above Specified Concentration Levels for Case 1b ............................................. 3.4

3.7 Aqueous Phase Source Release Rate for Case 1b................................................................... 3.4

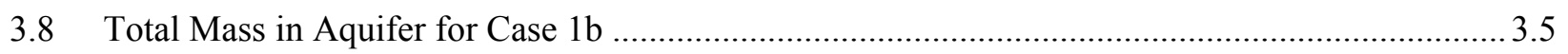

3.9 Maximum Carbon Tetrachloride Concentrationat ITRD Study Compliance Boundary

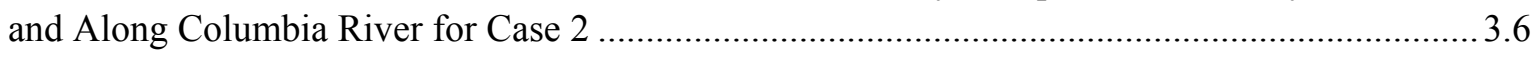

3.10 Aquifer Area Above Concentration Levels for Case 2 .......................................................... 3.7

3.11 Total Mass in Aquifer for Case 2 ....................................................................................... 3.7

3.12 Maximum Carbon Tetrachloride Concentration at ITRD Study Compliance Boundary and Along Columbia River for Case 3 ................................................................................ 3.8

3.13 Aquifer Area Above Concentration Levels for Case 3 ............................................................ 3.9

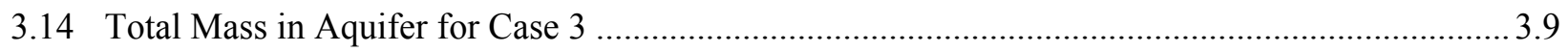

4.1 Carbon Tetrachloride Concentration for All Cases at ITRD Study Compliance Boundary and Along Columbia River.

\section{Tables}

2.1 Modeling Parameter Probability Distributions Used in ITRD Modeling Study.......................... 2.8

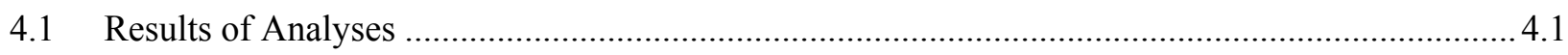




\subsection{Introduction}

The Hanford Carbon Tetrachloride Innovative Treatment Remediation Demonstration (ITRD) Program provided an initial evaluation of the nature and extent of carbon tetrachloride contamination in the unconfined aquifer in the 200 West Area of the Hanford Site (Truex et al. 2001). After the ITRD program ended, subsequent studies more closely examined the transport of carbon tetrachloride (CCl4) in the unconfined aquifer system. Those studies were undertaken to support strategic planning and provide guidance for the more robust modeling needed to obtain a final record of decision (ROD) for the carbon tetrachloride plume. This report documents the technical approach and results of this modeling. Section 1.1 provides an overview of the carbon tetrachloride plume, and Section 1.2 provides the scope of the report and the modeling studies performed.

\subsection{Overview of the Hanford Carbon Tetrachloride Plume}

In the 200 West Area at Hanford, carbon tetrachloride was disposed to the soil at several sites adjacent to the Z Plant (Plutonium Finishing Plant) during operations from 1955 to 1973. The carbon tetrachloride had been used in mixtures with other organics to recover plutonium from aqueous streams at Z Plant. The resultant organic liquid waste stream discharged to the disposal sites consisted primarily of carbon tetrachloride in mixtures with tributyl phosphate, dibutyl butyl phosphate, and lard oil.

The areal extent of the dissolved carbon tetrachloride plume is approximately $10 \mathrm{~km}^{2}$. Concentrations of dissolved carbon tetrachloride detected in the groundwater have been estimated to account for approximately $2 \%$ of the original carbon tetrachloride inventory.

Previous work (Swanson et al. 1999) considered an order-of-magnitude estimate of the 1990 inventory of carbon tetrachloride remaining in the subsurface using available groundwater concentration data, soil-gas concentration data, and well venting data. For the rough-order-of-magnitude estimates, it was assumed that 750,000 kg of carbon tetrachloride was discharged to the soil between 1955 and 1973 . Total atmospheric losses were estimated to be $21 \%$; the unsaturated zone inventory (in soil gas, soil moisture, and adsorbed phases) accounted for 12\%; and the dissolved phase in the aquifer was estimated at $2 \%$, leaving $65 \%$ of the original volume unaccounted for. However, the estimates did not consider nonaqueous-phase liquid (NAPL) organic residual saturation in the unsaturated zone, perched organic liquid on low-permeability lenses, or separate organic liquid present within the unconfined aquifer. Any or all of these forms of concentrated carbon tetrachloride may be present within the subsurface, though none has been observed.

\subsection{Scope of Report}

This report summarizes recent site-wide modeling studies that were part of an analysis that consisted of four model runs for analysis of the transport of the carbon-tetrachloride plume. The modeling approach, results, and general conclusions are described in Sections 2 and 3. Conclusions are presented in Section 4 and cited references in Section 5. Supporting documentation is provided in the appendix. 


\subsection{Technical Approach of Modeling Analysis}

The ITRD modeling study examined carbon tetrachloride concentrations at an arbitrary boundary between the 200 East and 200 West Areas (Truex et al. 2001). After that work was completed, questions arose concerning the concentrations reaching the Columbia River as well as the impacts of remediation options involving the removal or absence of the source. To address those questions, additional modeling studies were conducted using the site-wide groundwater model (SGM) with the modeling domain extended to the Columbia River. The original SGM grid and the arbitrary compliance boundary are shown in Figure 2.1 along with other details of the ITRD analysis (Truex et al. 2001).

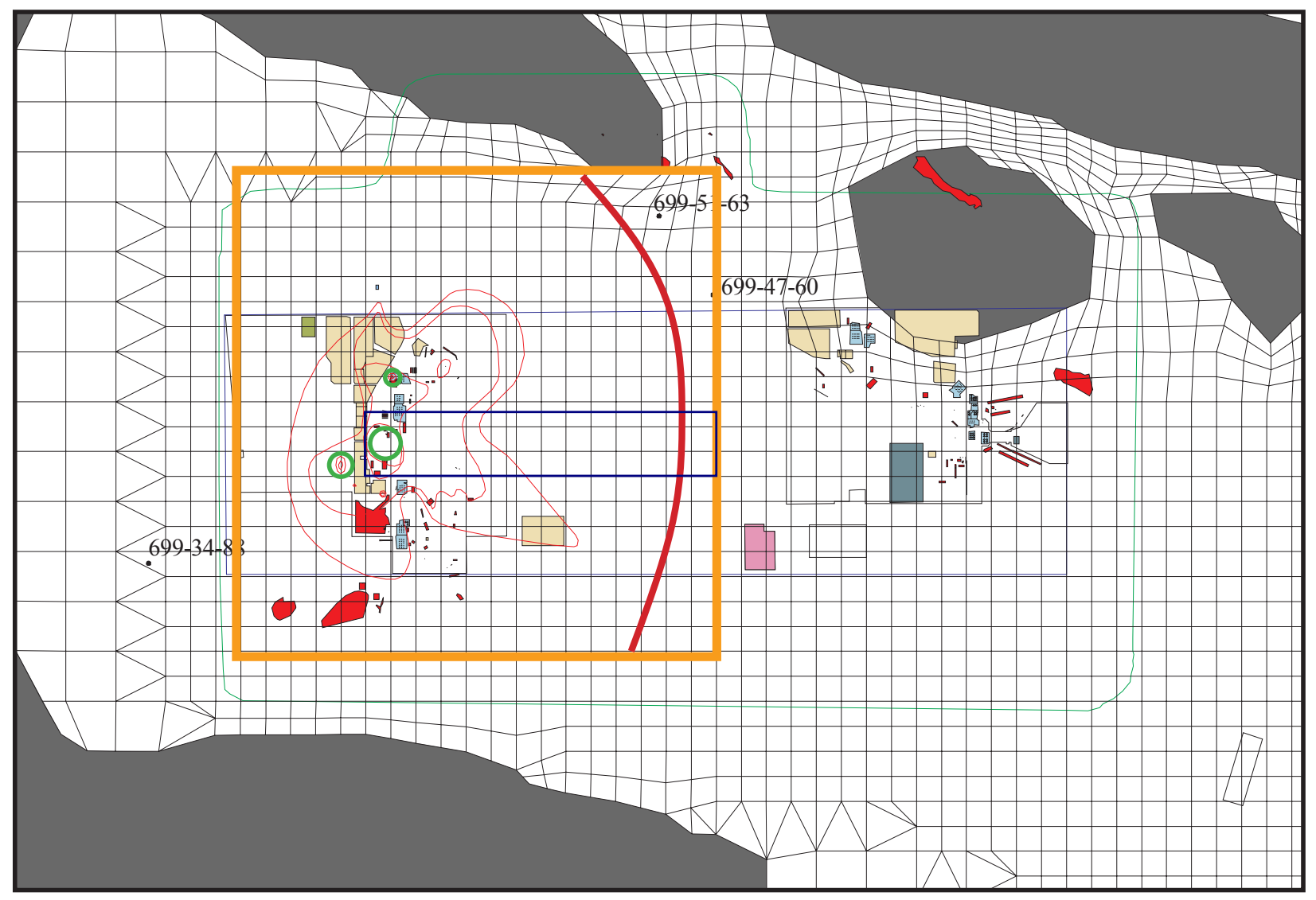

Current 375 m Transport Grid Area of Successive Grid Refinement to Represent Source Areas Compliance Boundary Area of Held Concentration for Source Determination Carbon Tetrachloride Plume Contours

Figure 2.1. SGM Model Grid of 200 East and West Areas. Overlays illustrate 1) the areal extent of carbon tetrachloride (thin red lines), 2) the area of grid refinement for the ITRD study (orange line), 3) the compliance analysis boundary for ITRD study (thick red line), and 4) the flow tube used for the one-dimensional modeling to examine the effect of parameter uncertainty and develop sampling strategies to minimize the number of three-dimensional model runs (blue box). 


\subsection{Cases Simulated}

Three general cases were evaluated as part of this modeling analysis:

- Case 1 (Continuing Source) involves a run to examine the effects of a continuing source. For this case the same assumptions used in the ITRD modeling are made (i.e., the groundwater system near the source is in equilibrium with the source). As a result, the continuing source can be simulated by holding all of the aquifer volume with concentrations at or above $3,000 \mu \mathrm{g} / \mathrm{L}$ at existing concentration levels until the remaining source inventory has been released $(487,500 \mathrm{~kg}$, or $\sim 65 \%$ of the estimated unaccounted for disposal mass of $750,000 \mathrm{~kg})$. Two variations of this case were investigated, each involving different assumptions for the controlling transport parameters to bound possible outcomes.

- Conservative variation with the natural attenuation parameters set to zero (i.e., $\mathrm{K}_{d}=0$ and $\mathrm{K}_{\mathrm{a}}=0$ ), where $\mathrm{K}_{\mathrm{a}}$ is the abiotic degradation rate and $\mathrm{K}_{\mathrm{d}}$ is the soil/water equilibrium sorption coefficient.

- Best-estimate variation using median values for the $\mathrm{K}_{\mathrm{a}}=0.00956 \mathrm{yr}^{-1}$ (reaction halftime = $72.5 \mathrm{yr}$ ) and $\mathrm{K}_{\mathrm{d}}=0.000322 \mathrm{~m}^{3} / \mathrm{kg}$ (retardation factor $=2.6$ ) determined from the Literature Review: Natural Attenuation Mechanisms and Rates for Chloromethane Subsurface Contamination at Hanford provided to the ITRD Technical Advisory Group and included as Appendix C in the ITRD report (Truex et al. 2001).

- Case 2 (Source Removal) simulates the effects of source removal. For this case the entire aquifer volume at or above the $3,000 \mu \mathrm{g} / \mathrm{L}$ contour was set to zero, simulating complete source removal. Thus, only the effects related to continued migration of the plume outside the source area were evaluated. For this case the conservative values for natural attenuation parameters were used $\left(\mathrm{K}_{\mathrm{d}}=0\right.$ \{retardation factor $\left.=1.0\right\}$ and $\mathrm{K}_{\mathrm{a}}=0$ \{no abiotic reactions $\left.\}\right)$.

- Case 3 (No Source and No Removal) is a run to simulate the effects of the assumption that the only remaining unaccounted-for inventory is in the existing plume. For this run the existing plume provides the initial conditions, and only the effects of the plume's migration without further source additions are simulated. As with Case 2, only the conservative variation for natural attenuation parameters was investigated (i.e., $\mathrm{K}_{\mathrm{d}}=0$ and $\mathrm{K}_{\mathrm{a}}=0$ ).

\subsection{Initial Conditions - Three-Dimensional Interpretation of Plume}

A geostatistical analysis of the existing carbon tetrachloride measurements performed as part of the initial ITRD modeling study (Truex et al. 2001) provided the three-dimensional (3-D) data set on carbon tetrachloride distribution used to approximate the 3-D initial conditions and source-term concentrations for the modeling analysis described in this report.

A 3-D distribution of carbon tetrachloride in 1993 was needed to provide the initial conditions for flow and transport modeling. This was developed from data collected from the wells shown in Figure 2.2 (Truex et al. 2001). The geostatistical approach is fully discussed in the ITRD report. Information on the distribution of carbon tetrachloride with depth was not available for most of the wells, and only one measurement was available near the water table. Carbon tetrachloride concentrations for these 121 wells are from the Groundwater Monitoring Project database and restricted to measurements from 1993. Data for distribution of carbon tetrachloride with depth were taken from Swanson et al. (1999, Appendix A). 


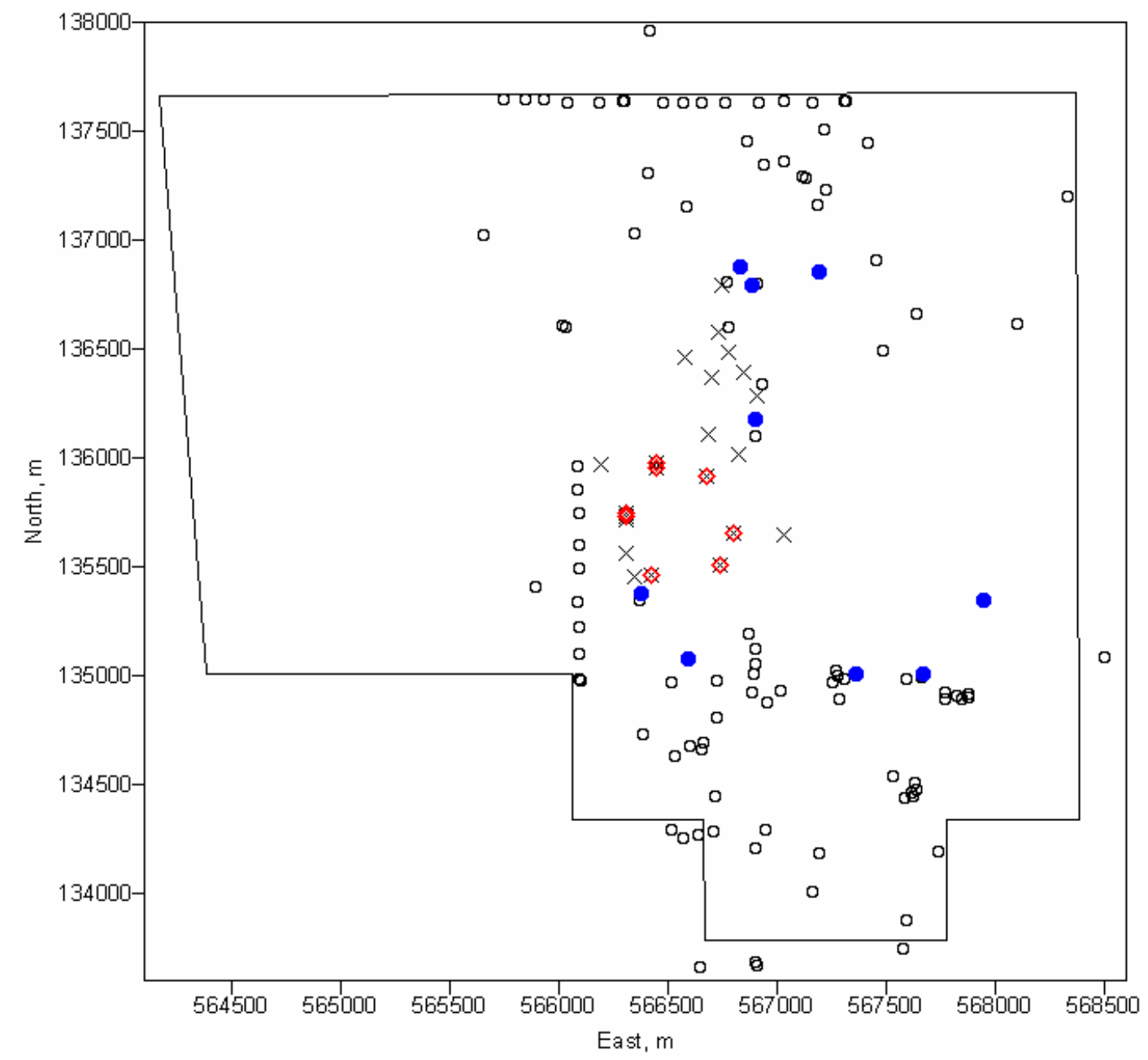

Figure 2.2. Map of Carbon Tetrachloride Concentration Data Used in Geostatistical Analysis. The blank circles and crosses represent the 2-D outer and central wells; the blue solid circles represent the nine 3-D outer wells and red diamonds the eight 3-D central wells. Central wells have concentrations exceeding $1000 \mu \mathrm{g} / \mathrm{L}$; 3-D wells have carbon tetrachloride concentration data at depths greater than $5 \mathrm{~m}$ (from Truex et al. 2001).

Only eight central wells and nine outer wells have available 3-D carbon tetrachloride data in that data set. Because of the scarcity of deep carbon tetrachloride data where the location of the measurement is known with any confidence, it was impossible to restrict the data to 1993 for deep measurements, so the average of all measurements made at various times at a given 3-D location (i.e., for a given well and depth) were used. Even so, only 58 data points are available where the depth of the measurement was more than $5 \mathrm{~m}$ below the water table. The 58 data points are distributed among the 17 locations (eight central and nine outer wells) with deep carbon tetrachloride measurements.

One hundred realizations were generated of the 3-D spatial distribution of the carbon tetrachloride concentration at a grid node spacing of 50 by $50 \mathrm{~m}$ horizontally and $5 \mathrm{~m}$ vertically. A total of 65,280 ( 51 by 64 by 20 ) grid nodes were simulated in each realization. Horizontal and vertical displays of the median carbon tetrachloride from the first 100 realizations are shown in Figure 2.3. 

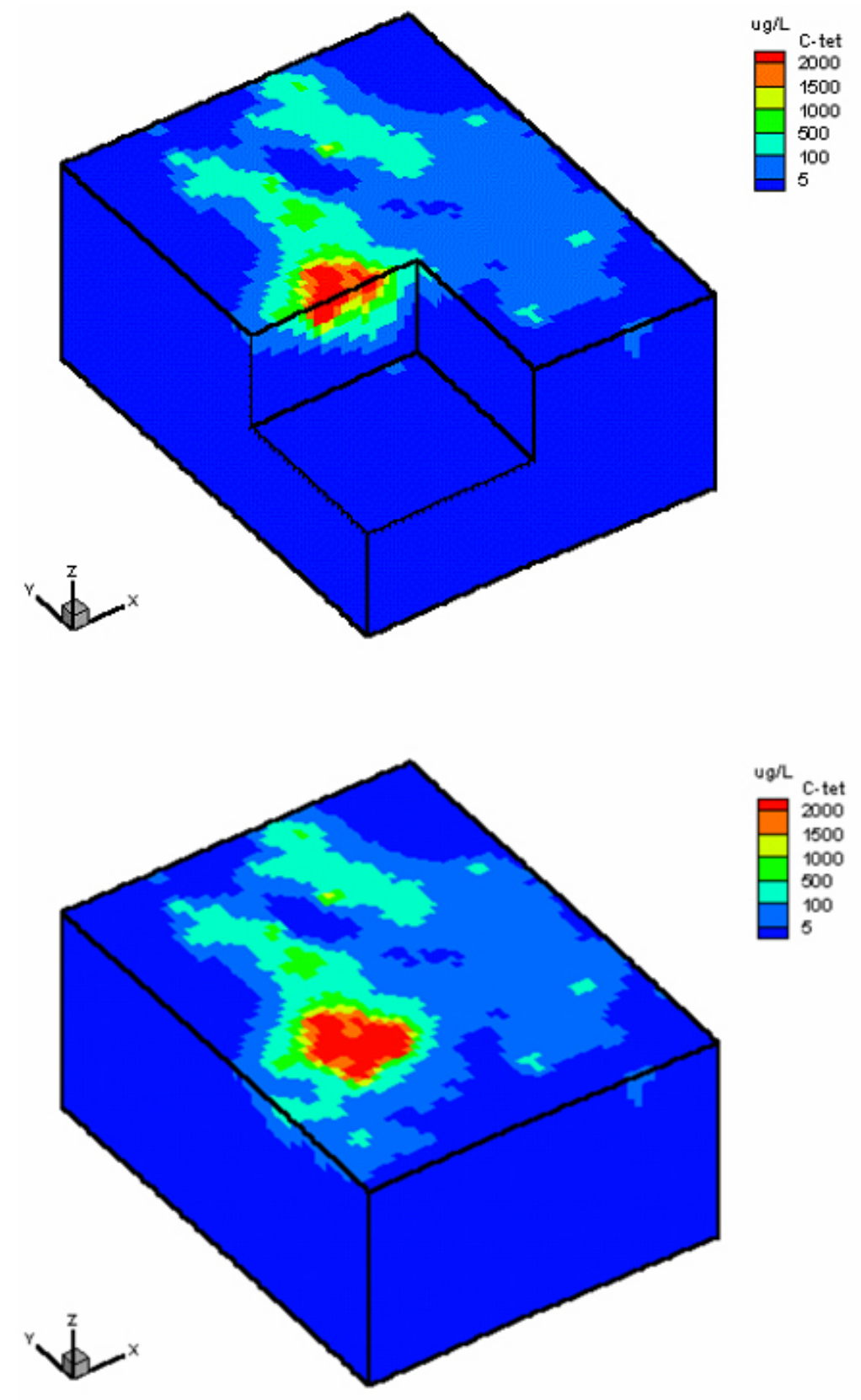

Figure 2.3. Block Diagrams Showing Median of First 100 Geostatistical Simulations of 3-D Carbon Tetrachloride Distribution

Figure 2.4 from the ITRD study shows the simulation median concentrations and the 2-D carbon tetrachloride inventory from vertical summation of simulated 3-D median carbon tetrachloride. An analysis of three possible source areas, labeled Block 1, Block 2, and Block 3 in Figure 2.4, identified Block 1 as the main source with an area approaching $1 \mathrm{~km}^{2}$. The proportion of carbon tetrachloride inventory in Blocks 2 and 3 together is less than 0.1 of the total inventory; Block 1 contains nearly 0.8 of the total. 


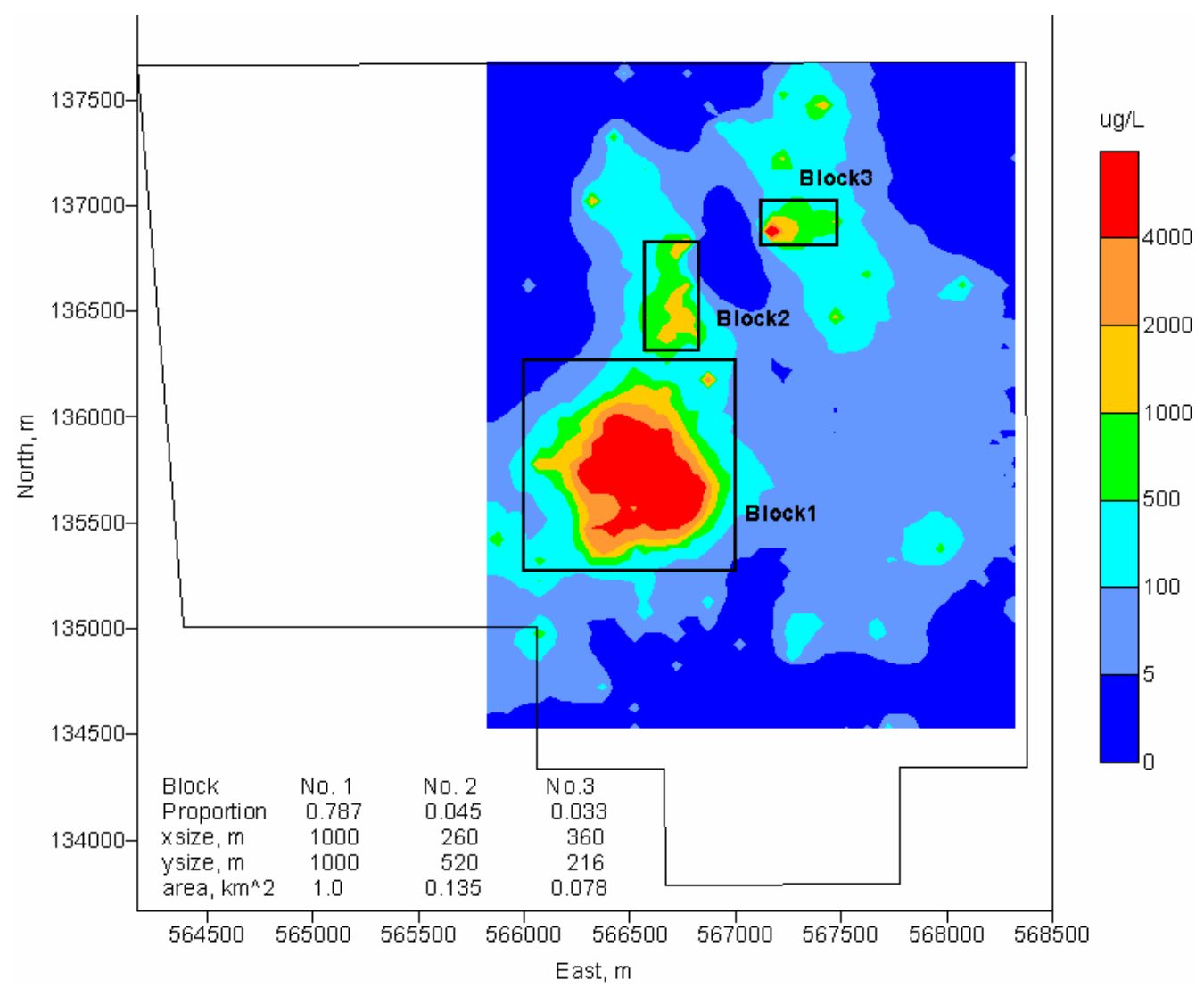

Figure 2.4. Vertical Summation of Simulated Median Carbon Tetrachloride Concentration and Proportion Within Three Source Blocks to Total Summed Concentration

\subsection{Model, Grid, and Hypothetical Points of Analysis}

Several hypothetical points and boundaries in the current and previous ITRD analyses are shown in Figure 2.1. These include the areal extent of carbon tetrachloride (thin red lines), the area of grid refinement for the original ITRD study (orange line), the arbitrary compliance analysis boundary (thick red line) for the original ITRD study, and the flow tube (blue box) used for the 1-D modeling to examine the effects of parameter uncertainty and to develop sampling strategies to minimize the number of 3-D model runs. The thin green line in Figure 2.1 illustrates the outer boundaries of the proposed core zone around the 200 Area Plateau WMA. The other important boundary is the Columbia River, which is not shown in the figure.

The initial conditions and refined grid for the smaller-scale subregion model used in the previous ITRD modeling study (orange boundary of Figure 2.1) are shown in Figure 2.5. This previous modeling, as well as that documented in this report, used the model from the earlier site-wide plume analysis (Cole et al. 1997). The background grid in Figure 2.1 is the transport grid for the previous modeling. It can be seen that the existing grid in the area of the source is the same scale as the primary source area (i.e., the central dark-green circle of Figure 2.1), and as a result some refinement was needed to properly represent the source area for evaluating the three cases investigated in this study. Figure 2.6 shows the slightly refined SGM grid with expanded sections that illustrate the refinement for the source areas and the median realization for initial conditions. 


\section{Secondary Source Areas}

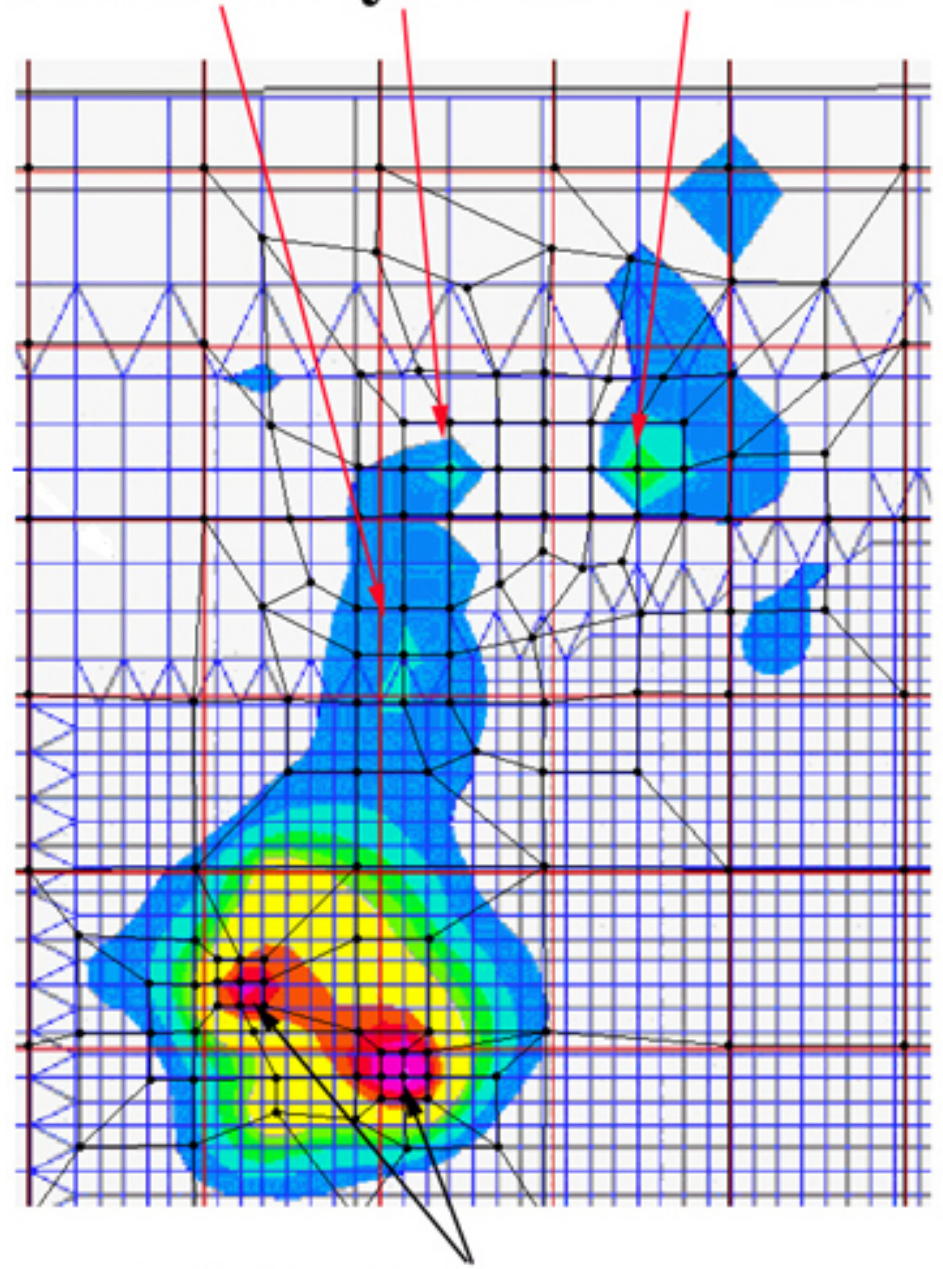

Main Source Area

Figure 2.5. Initial Conditions (upper $5 \mathrm{M}$ ) for Current and Previous ITRD Modeling with Fine Grid Used in Previous ITRD Subregion Modeling (orange boundary in Figure 2.1); also shows the main and secondary source areas.

\subsection{Natural Attenuation Modeling Parameters}

In addition to the geostatistical simulations of the carbon tetrachloride source volumes, the ITRD study examined realizations of several other modeling parameters needed for the 1-D Monte Carlo flow and transport study (Truex et al. 2001). That analysis examined the best-estimate values for two parameters, the $\mathrm{K}_{\mathrm{d}}$ for carbon tetrachloride and the abiotic degradation rate of carbon tetrachloride, or $\mathrm{K}_{\mathrm{a}}$, which were used in this study. Truex et al. (2001) identified the minimum, maximum, and most likely values of each parameter, which were then used to characterize the probability distributions. These values and distributions are shown in Table 2.1 and Figure 2.7, respectively. 


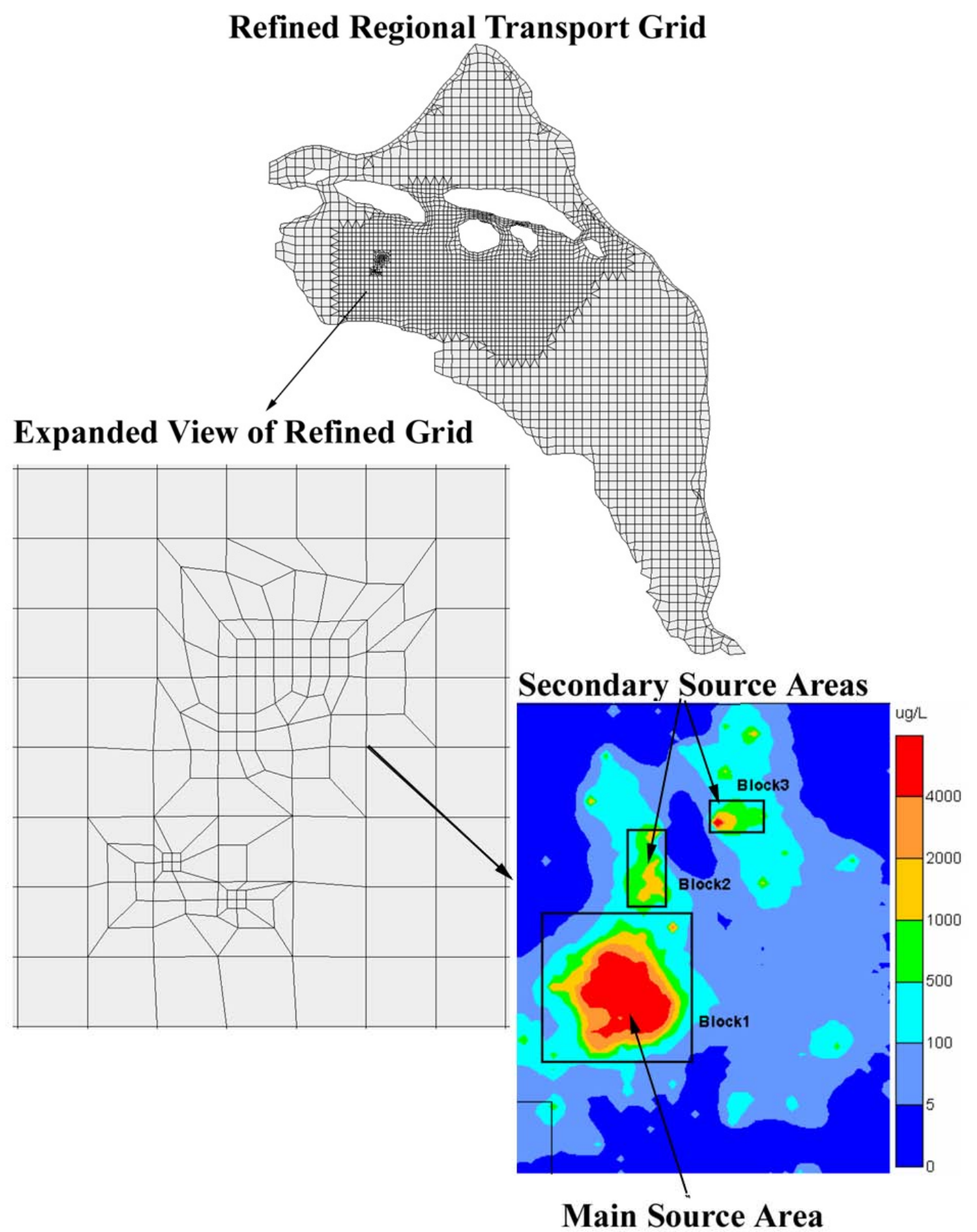

Figure 2.6. Refined SGM Grid Used in this Study with Expanded Sections to Illustrate the Refinement for Source Areas and Matching Realization Used for Initial Conditions 
Table 2.1. Modeling Parameter Probability Distributions Used in ITRD Modeling Study

\begin{tabular}{||l|c|c|c|c||}
\hline \multicolumn{1}{|c|}{ Parameter } & Distribution Type & Minimum & Maximum & Most Probable \\
\hline $\mathrm{CCl}_{4} \mathrm{~K}_{\mathrm{d}}(\mathrm{L} / \mathrm{kg})$ & Triangular & 0.016 & 0.83 & 0.12 \\
\hline $\mathrm{CCl}_{4} \mathrm{~K}_{\mathrm{a}}$ (per day) & Triangular & $6.50 \mathrm{E}-06$ & $5.30 \mathrm{E}-05$ & $1.90 \mathrm{E}-05$ \\
\hline
\end{tabular}
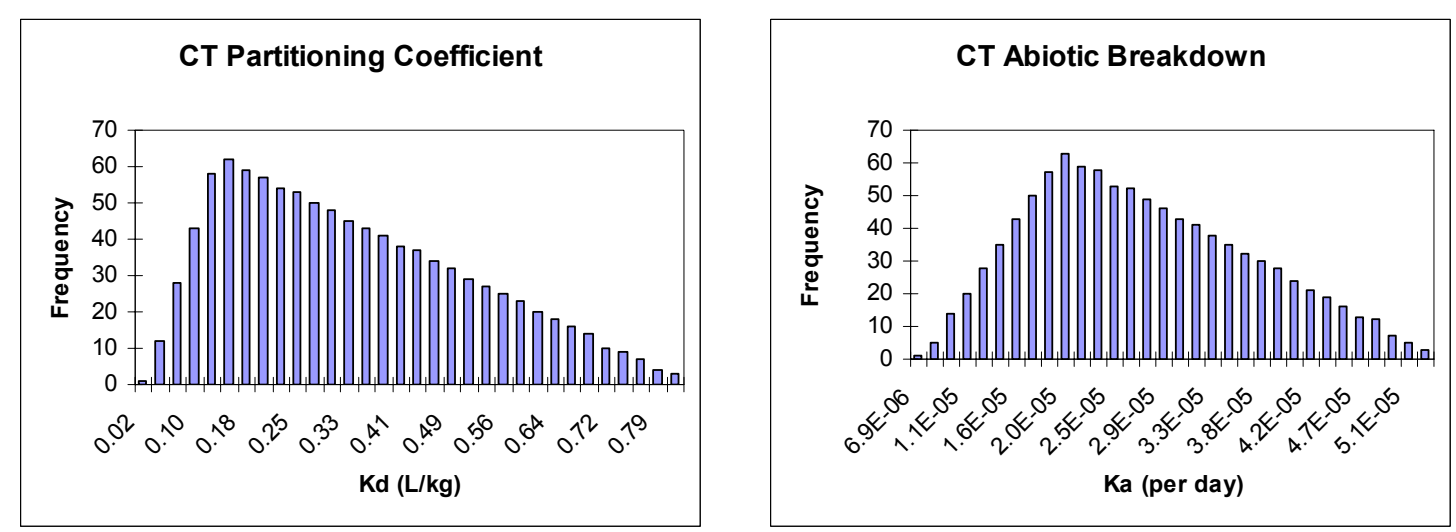

Figure 2.7. Histograms of 1000 Simulated Values of Each of the Four Input Parameters Used in the ITRD Flow and Transport Modeling

\subsection{Other Modeling Considerations}

The model used the same future disposal assumptions and addressed a transient time period extending from current conditions to the next $\sim 1500$ years. Results include plots of maximum concentration versus time at selected locations and plan view concentration distribution plots at various times (e.g., 5, 10, 50, $100,200 \ldots$ years) until intersection with the Columbia River. 


\subsection{Results}

This section presents results for the three general simulation cases used in this modeling study. Key results for Case 1a, assuming a continuing source and $\mathrm{K}_{\mathrm{d}}$ and $\mathrm{K}_{\mathrm{a}}$ equal to zero, are discussed in Section 3.1, and Case 1b, with a continual source and a median $\mathrm{K}_{d}$ and $\mathrm{K}_{\mathrm{a}}$, is presented in Section 3.2. Case 2, which assumes no continuing source, but source removal and $\mathrm{K}_{d}$ and $\mathrm{K}_{\mathrm{a}}$ equal to zero, is discussed in Section 3.3, and Case 3, assuming no continuing source, no source removal, and $\mathrm{K}_{\mathrm{d}}$ and $\mathrm{K}_{\mathrm{a}}$ equal to zero, is presented in Section 3.4.

\subsection{Case 1a}

Key results for Case 1a, assuming a continuing source and $\mathrm{K}_{\mathrm{d}}$ and $\mathrm{K}_{\mathrm{a}}$ equal to zero, are discussed in this section and illustrated in Figures 3.1 through 3.4. Simulation results for this case indicated that maximum predicted carbon tetrachloride concentrations would exceed the current benchmark maximum concentration limit (MCL) of $5 \mu \mathrm{g} / \mathrm{L}$ at the arbitrary analysis boundary (Figure 3.1a). Within the regional

(a)

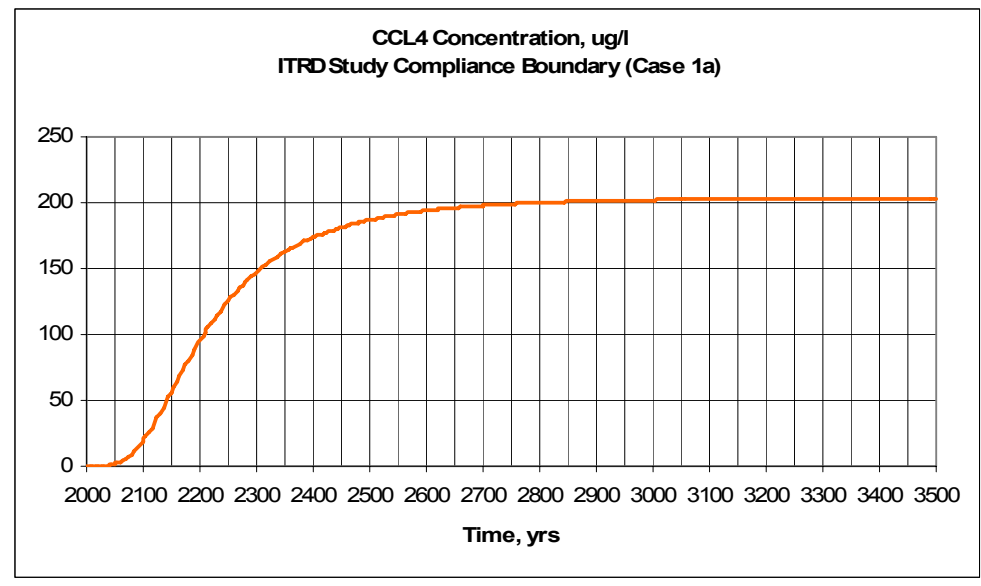

(b)

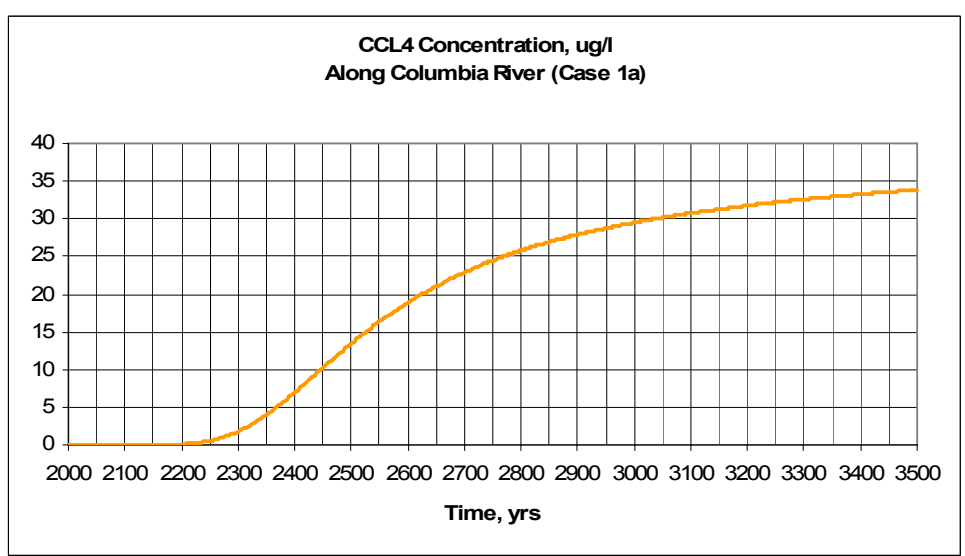

Figure 3.1. Carbon Tetrachloride Concentrations at ITRD Study Compliance Boundary (a) and Along Columbia River (b) for Case 1a 


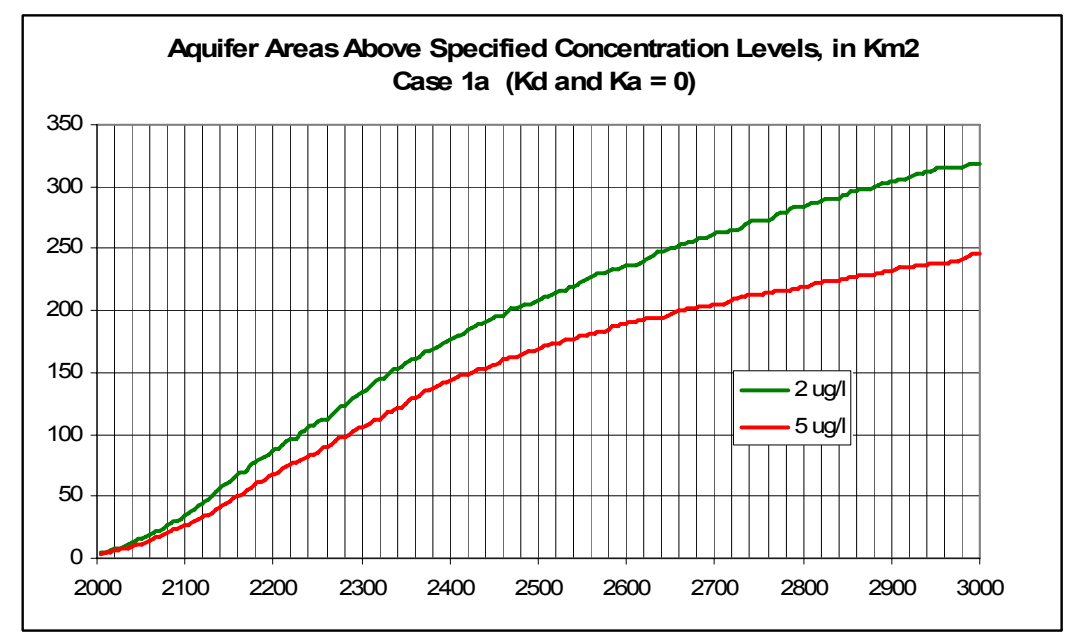

Figure 3.2. Aquifer Areas Above Specified Concentration Levels $\left(\mathrm{km}^{2}\right)$ for Case 1a

(a)

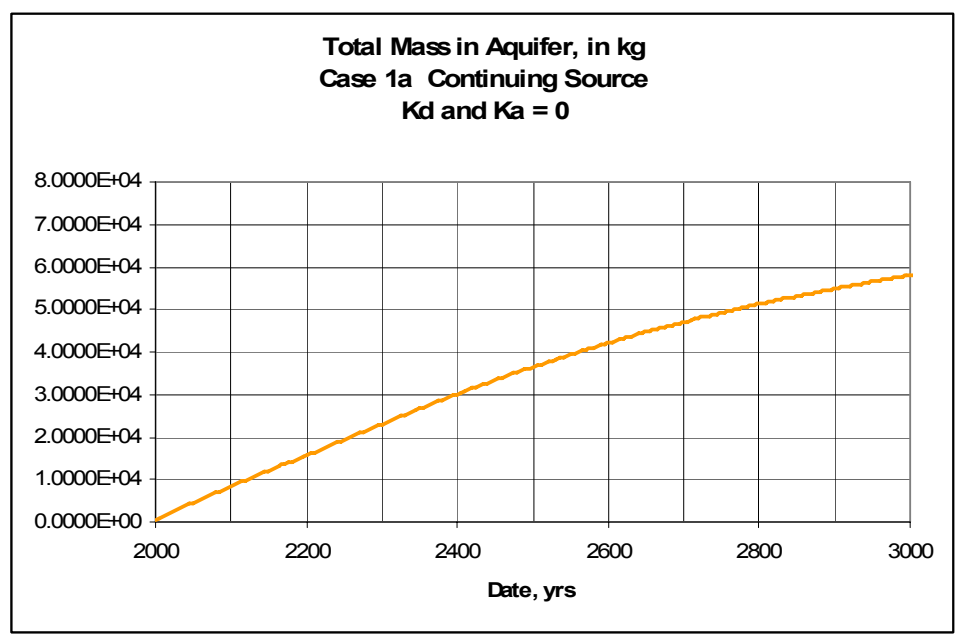

(b)

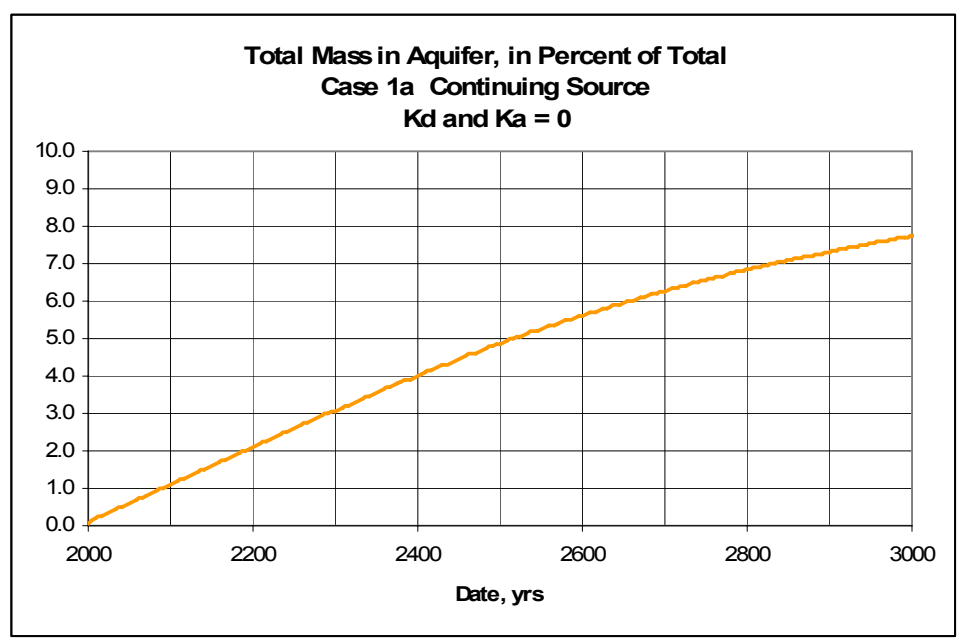

Figure 3.3. Total Mass in Aquifer $(a=k g ; b=\%$ of total), Case $1 \mathrm{a}$ 


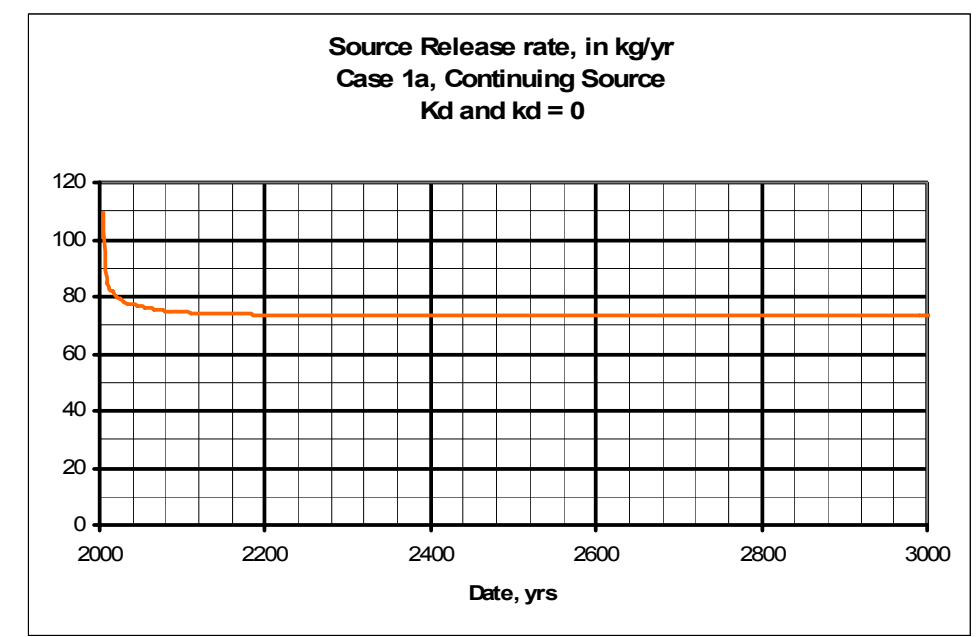

Figure 3.4. Source Release Rate (kg/yr) for Case 1a

scale model presented here, maximum concentrations at the analysis boundary would reach about $200 \mu \mathrm{g} / \mathrm{L} \sim 1000$ years after the start of simulations (Figure 3.1a). Maximum concentrations estimated in the regional scale model just before discharging into the Columbia River near the Hanford Town Site exceed the benchmark MCL $(5 \mu \mathrm{g} / \mathrm{L})$ less than 400 years after the start of the simulation, reaching about $30 \mu \mathrm{g} / \mathrm{L}$ at 1000 years and about $34 \mu \mathrm{g} / \mathrm{L}$ at 1500 years (Figure 3.1b). The resulting aquifer area that would exceed the benchmark MCL $(5 \mu \mathrm{g} / \mathrm{L})$ in the regional scale was estimated at about $247 \mathrm{~km}^{2}$ $\left(95.4 \mathrm{mi}^{2}\right) 1000$ years after simulations began (Figure 3.2). The resulting aquifer area that would exceed a $2 \mu \mathrm{g} / \mathrm{L}$ concentration level was estimated to be about $318 \mathrm{~km}^{2}\left(122.8 \mathrm{mi}^{2}\right) 1000$ years after the start of simulation (Figure 3.2).

Mass in the aquifer ranged from an initial condition of about $542 \mathrm{~kg}$ at the start of the simulation to about $58,050 \mathrm{~kg}$ in the year 3000 (Figure 3.3a). These mass estimates (Figure 3.3b) represent about 0.07 and 7.8 percent of the total estimated historical inventory release (that is, $\sim 750,000 \mathrm{~kg}$ ).

With the assumption of a continuing source, as analyzed in this case, estimated mass loading from the source zone would reach a maximum loading rate of about $73 \mathrm{~kg} / \mathrm{yr}$ (Figure 3.4). This loading rate indicates that, with this simplifying assumption, only a very small percentage $(0.00973 \%)$ of the total estimated historical inventory release (that is, $\sim 750,000 \mathrm{~kg}$ ) would be released each year from the highest concentration volumes within the groundwater source zones.

\subsection{Case 1b}

Key results for Case $1 b$, which assumes a continual source and median $K_{d}$ and $K_{a}$, are discussed in this section and illustrated in Figures 3.5 through 3.8. Simulations for this case (Figure 3.5) produced a maximum predicted concentration of $\sim 4.5 \mu \mathrm{g} / \mathrm{L}$, which would not exceed the current benchmark MCL of $5 \mu \mathrm{g} / \mathrm{L}$ at the arbitrary analysis boundary. Thus, the maximum predicted concentration would not reach the Columbia River at any substantial level within the 1000-year period of analysis and would never be close to MCL. The resulting aquifer area (Figure 3.6) that would exceed the benchmark MCL $(5 \mu \mathrm{g} / \mathrm{L})$ was estimated to be about $13.6 \mathrm{~km}^{2}\left(5.3 \mathrm{mi}^{2}\right) \sim 600$ years after the start of simulations. The resulting aquifer area that would exceed a $2 \mu \mathrm{g} / \mathrm{L}$ concentration level was estimated to be about $20.8 \mathrm{~km}^{2}\left(8.0 \mathrm{mi}^{2}\right)$ 


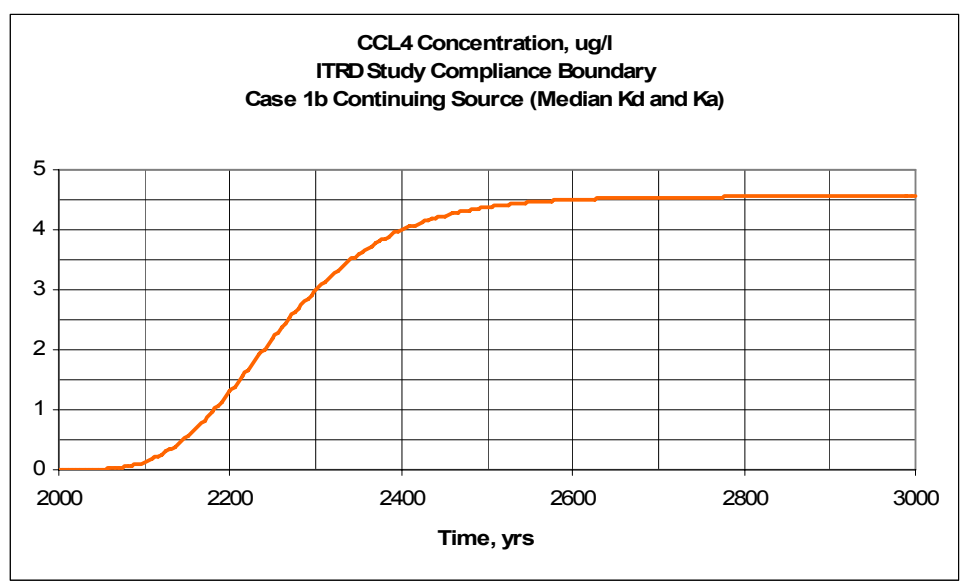

Figure 3.5. Carbon Tetrachloride Concentration at ITRD Study Compliance Boundary $(\mu \mathrm{g} / \mathrm{L})$ for Case $1 \mathrm{~b}$

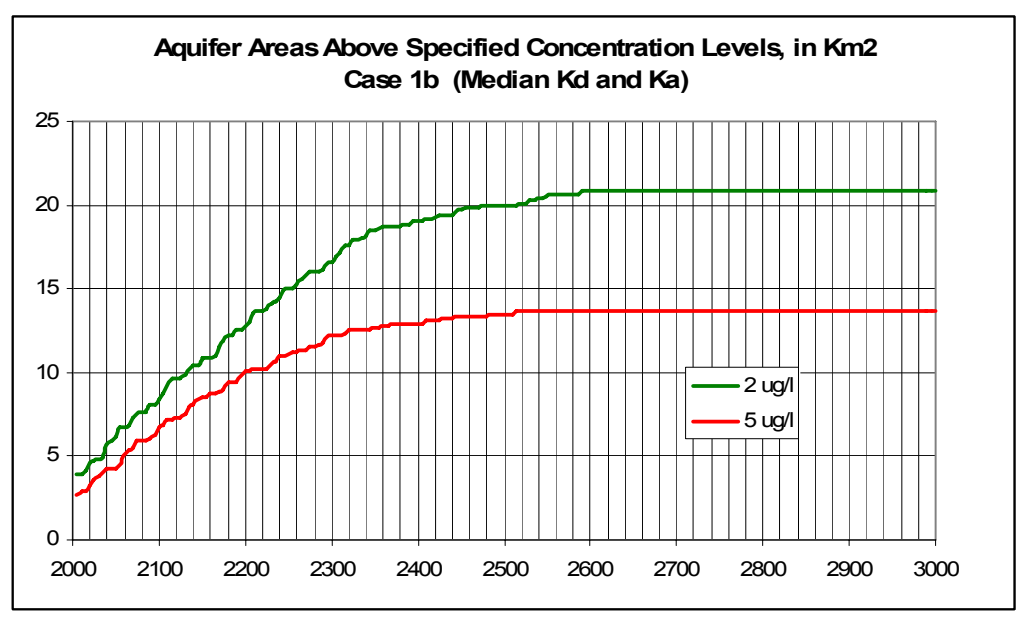

Figure 3.6. Aquifer Areas Above Specified Concentration Levels $\left(\mathrm{km}^{2}\right)$ for Case $1 \mathrm{~b}$

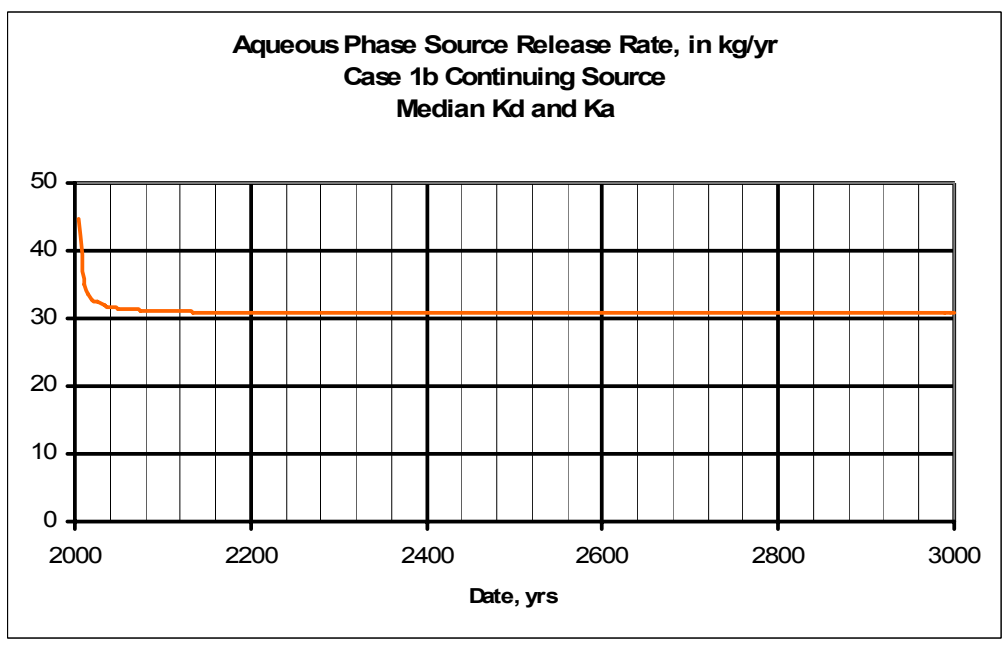

Figure 3.7. Aqueous Phase Source Release Rate (kg/yr) for Case $1 \mathrm{~b}$ 
(a)

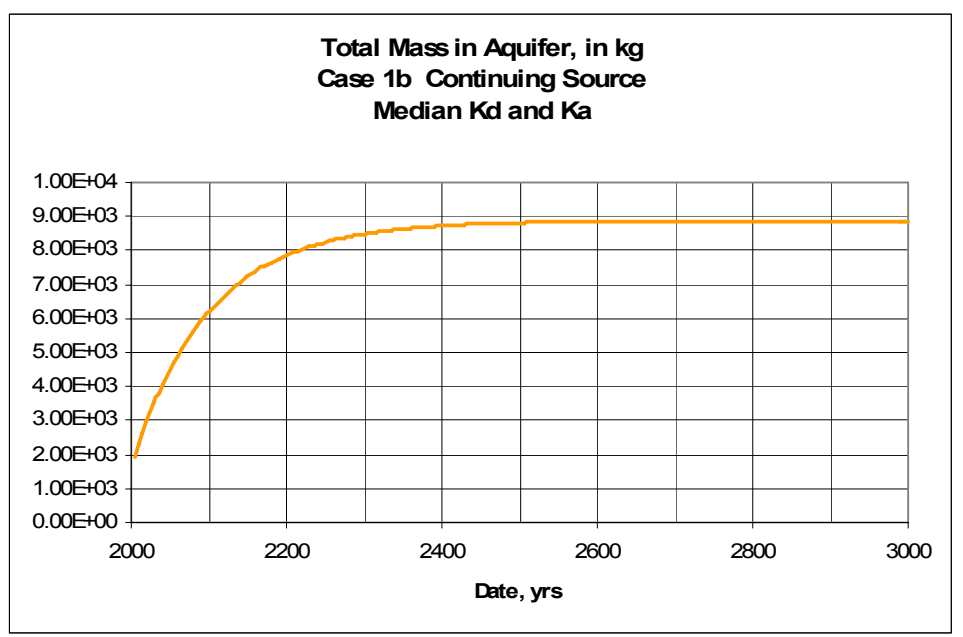

(b)

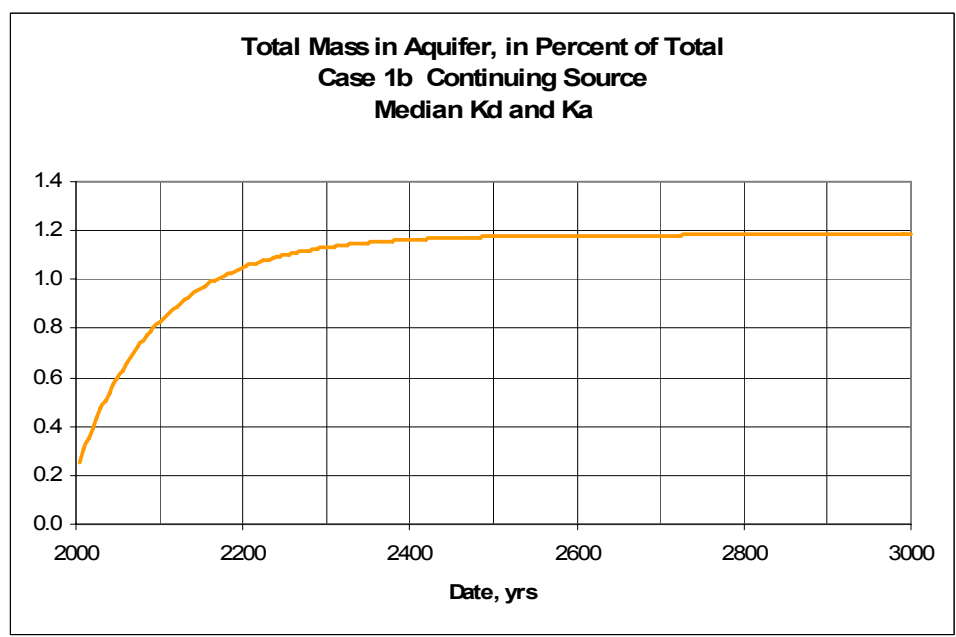

Figure 3.8. Total Mass in Aquifer $(a=k g ; b=\%$ of total) for Case $1 b$

$\sim 600$ years after the start of simulation. These areas of elevated concentrations reached a steady-state condition $\sim 600$ years after the simulation began, when the decay due to abiotic degradation within the plume reached equilibrium with mass production rates in the source areas of $30.9 \mathrm{~kg} / \mathrm{yr}$ (Figure 3.7). This loading rate indicates that, with this simplifying assumption, only a very small percentage $(0.0041 \%)$ of the total estimated historical inventory $(\sim 750,000 \mathrm{~kg})$ would be released each year from the highest concentration volumes in the groundwater source zones. Mass in the aqueous phase of the aquifer ranged from an initial condition of $\sim 500 \mathrm{~kg}$ to $\sim 3372 \mathrm{~kg}$ in the year 3000 (Figure 3.8a). These mass estimates (Figure $3.8 \mathrm{~b})$ represent 0.07 and $0.45 \%$ of the total estimated historical inventory release $(\sim 750,000 \mathrm{~kg})$.

\subsection{Case 2}

Key results for Case 2, which assumes no continuing source, source removal, and $\mathrm{K}_{\mathrm{d}}$ and $\mathrm{K}_{\mathrm{a}}$ equal to zero, are discussed in this section and illustrated in Figures 3.9 through 3.11. Simulation results of this case (Figure 3.9a) predicted a concentration maximum that slightly exceeds $(\sim 6.25 \mu \mathrm{g} / \mathrm{L})$ the current benchmark MCL of $5 \mu \mathrm{g} / \mathrm{L}$ at the arbitrary analysis boundary between the 200 East and West Areas in 
(a)

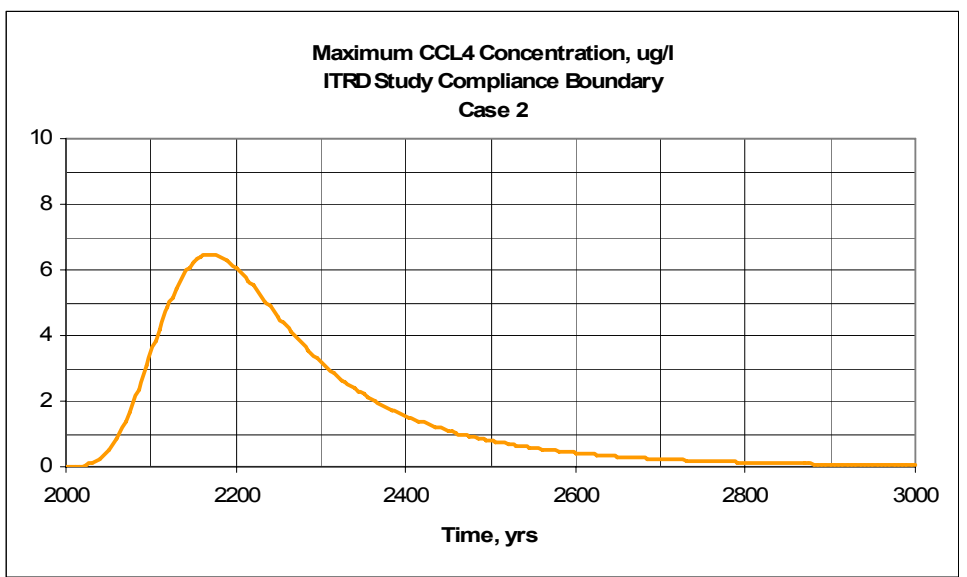

(b)

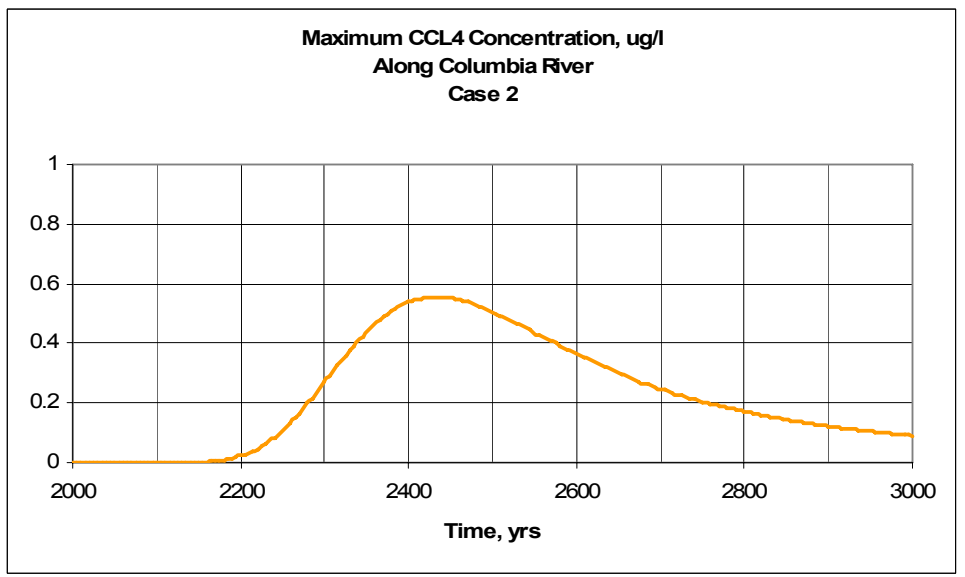

Figure 3.9. Maximum Carbon Tetrachloride Concentration $(\mu \mathrm{g} / \mathrm{L})$ at

(a) ITRD Study Compliance Boundary and (b) Along Columbia River for Case 2

about 180 years. Estimated concentrations at discharge areas near the Columbia River (Figure 3.9b) are not predicted to come close to reaching the benchmark MCL of $5 \mu \mathrm{g} / \mathrm{L}$ - they reach a maximum concentration of about $0.5 \mu \mathrm{g} / \mathrm{L}$ a little over 400 years after the start of the simulation. The resulting aquifer area that would exceed the benchmark MCL $(5 \mu \mathrm{g} / \mathrm{L})$ in the regional scale was estimated to be about $10.8 \mathrm{~km}^{2}\left(4.2 \mathrm{mi}^{2}\right) 115$ years after the start of simulations (Figure 3.10). The aquifer area that would exceed a $2 \mu \mathrm{g} / \mathrm{L}$ concentration level was estimated to be about $18.4 \mathrm{~km}^{2}\left(7.1 \mathrm{mi}^{2}\right)$ approximately 180 years after the start of simulation, and groundwater concentrations were predicted to drop below 5 and $2 \mu \mathrm{g} / \mathrm{L}$ about 320 and 520 years, respectively, after the start of simulations (Figure 3.10).

Mass in the aquifer ranged from an initial condition of about $543 \mathrm{~kg}$ at the start of the simulation to about $200 \mathrm{~kg}$ in the year 3000 (Figure 3.11a). These mass estimates represent 0.07 and $0.03 \%$ (Figure $3.11 \mathrm{~b}$ ) of the total estimated historical inventory release (that is, $\sim 750,000 \mathrm{~kg}$ ). 


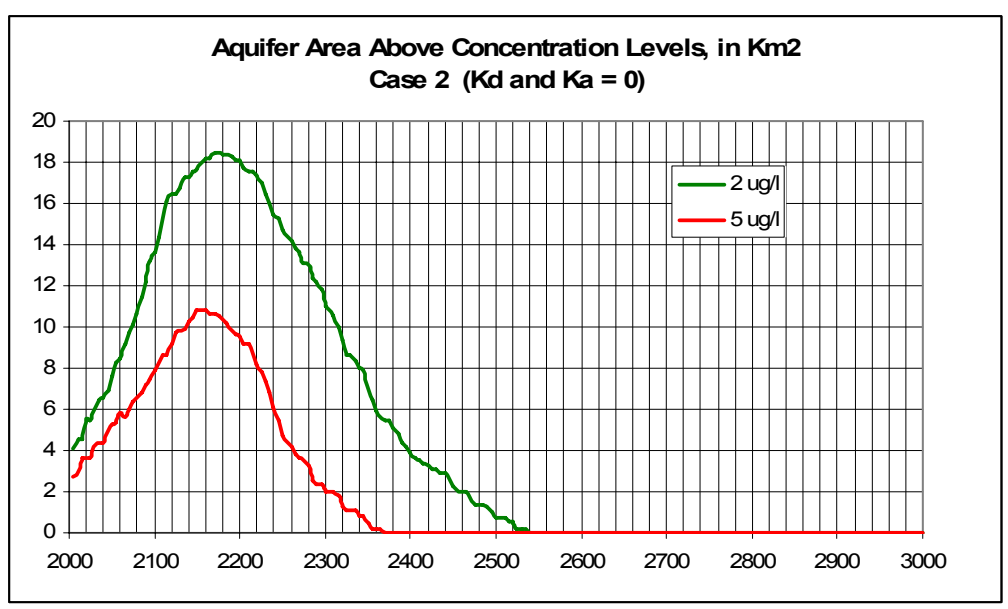

Figure 3.10. Aquifer Area Above Concentration Levels $\left(\mathrm{km}^{2}\right)$ for Case 2

(a)

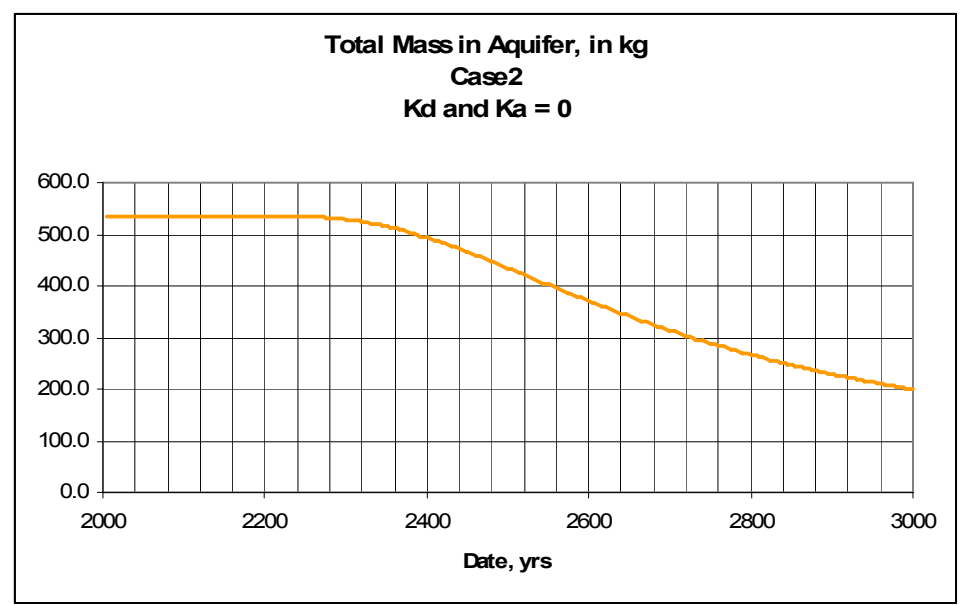

(b)

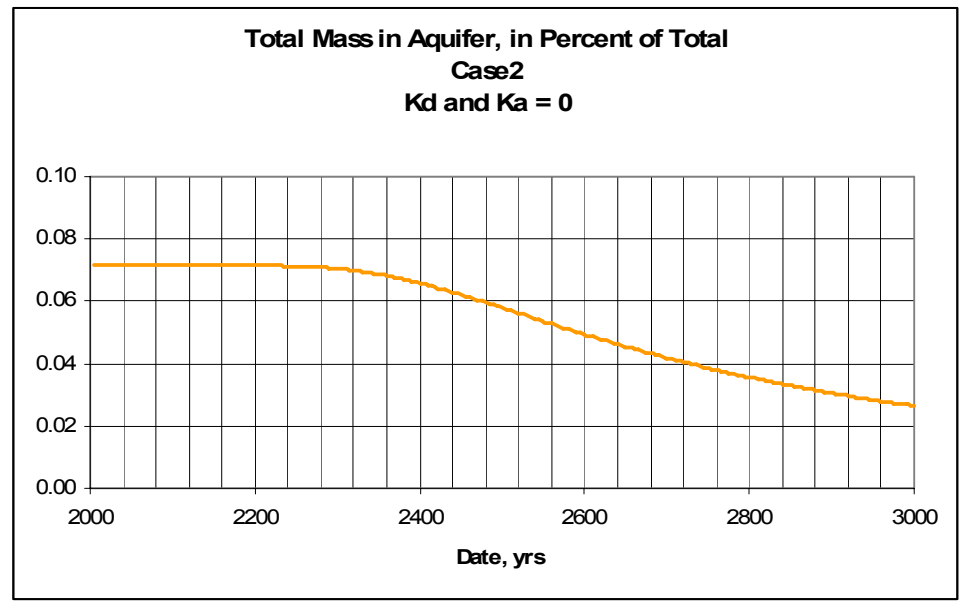

Figure 3.11. Total Mass in Aquifer $(a=k g ; b=\%$ of total) for Case 2 


\subsection{Case 3}

Key results for Case 3, which assumes no continuing source, no source removal, and $\mathrm{K}_{\mathrm{d}}$ and $\mathrm{K}_{\mathrm{a}}$ equal to zero, are discussed in this section and illustrated in Figures 3.12 through 3.14. Simulation results for this case (Figure 3.12a) predicted concentrations slightly exceeding the current benchmark MCL of $5 \mu \mathrm{g} / \mathrm{L}$ at the arbitrary analysis boundary between the 200 East and West Areas. Maximum concentrations at the arbitrary analysis boundary would reach about $6.25 \mu \mathrm{g} / \mathrm{L} 180$ years after the start of the simulation. Like Case 2, estimated concentrations at discharge areas near the Columbia River are predicted to be about $0.5 \mu \mathrm{g} / \mathrm{L}$, which is well below the benchmark MCL of $5 \mu \mathrm{g} / \mathrm{L}$ within the period of analysis (Figure 3.12b). The resulting aquifer area that would exceed the benchmark MCL $(5 \mu \mathrm{g} / \mathrm{L})$ is $\sim 10.8 \mathrm{~km}^{2}\left(4.2 \mathrm{mi}^{2}\right)$ about 150 years after the start of simulations (Figure 3.13). The resulting aquifer area that would exceed a $2 \mu \mathrm{g} / \mathrm{L}$ concentration level was estimated to be about $18.4 \mathrm{~km}^{2}\left(7.1 \mathrm{mi}^{2}\right)$ about 180 years after the start of simulations (Figure 3.13). As in Case 2, groundwater concentrations were predicted to drop below 5 and $2 \mu \mathrm{g} / \mathrm{L}$ about 320 and 520 years, respectively, after the start of simulations.

Mass in the aquifer ranged from initial conditions of $\sim 536 \mathrm{~kg}$ at the start of the simulation to $\sim 199 \mathrm{~kg}$ in the year 3000 (Figure 3.14a). These mass estimates represent 0.07 and $0.03 \%$ (Figure 3.14b) of the total estimated historical inventory release $(\sim 750,000 \mathrm{~kg})$.

(a)

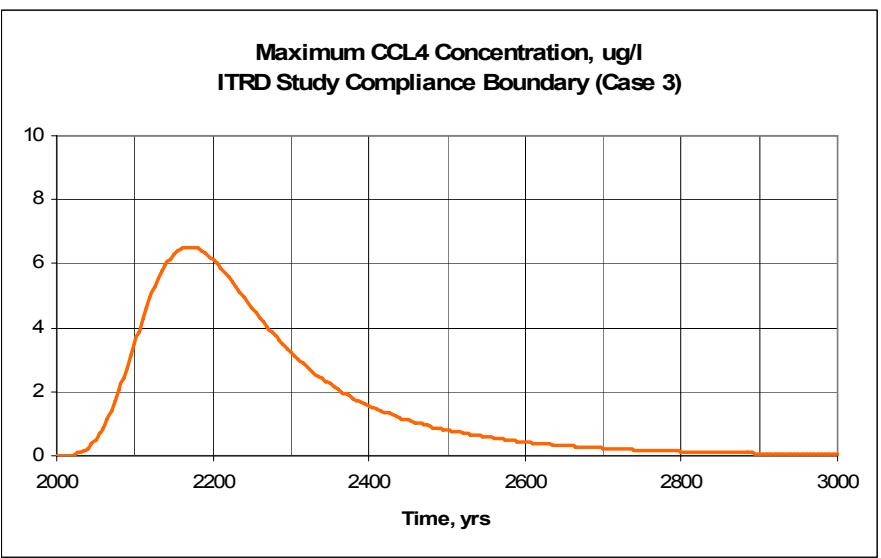

(b)

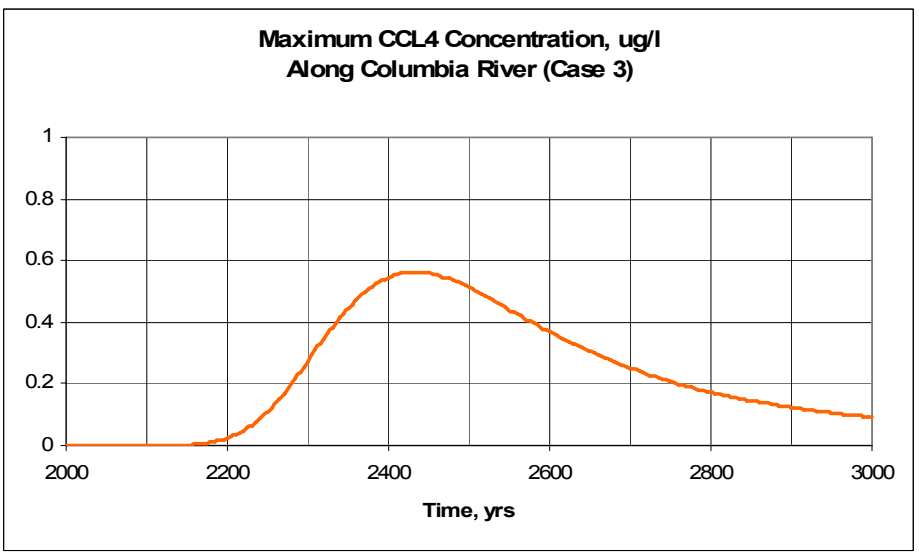

Figure 3.12. Maximum Carbon Tetrachloride Concentration $(\mu \mathrm{g} / \mathrm{L})$ at (a) ITRD Study Compliance Boundary and (b) Along Columbia River for Case 3 


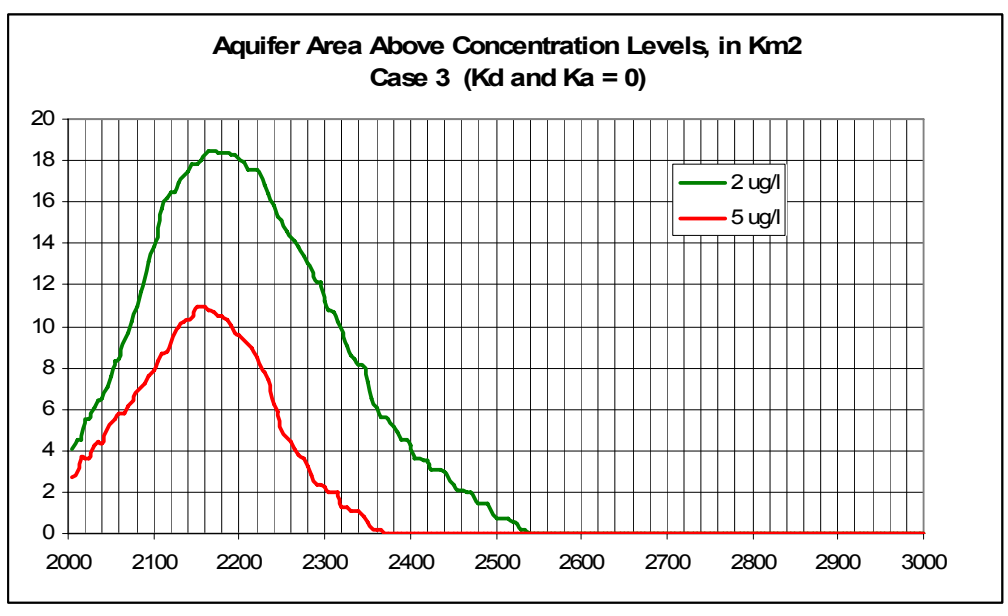

Figure 3.13. Aquifer Area Above Concentration Levels $\left(\mathrm{km}^{2}\right)$ for Case 3

(a)

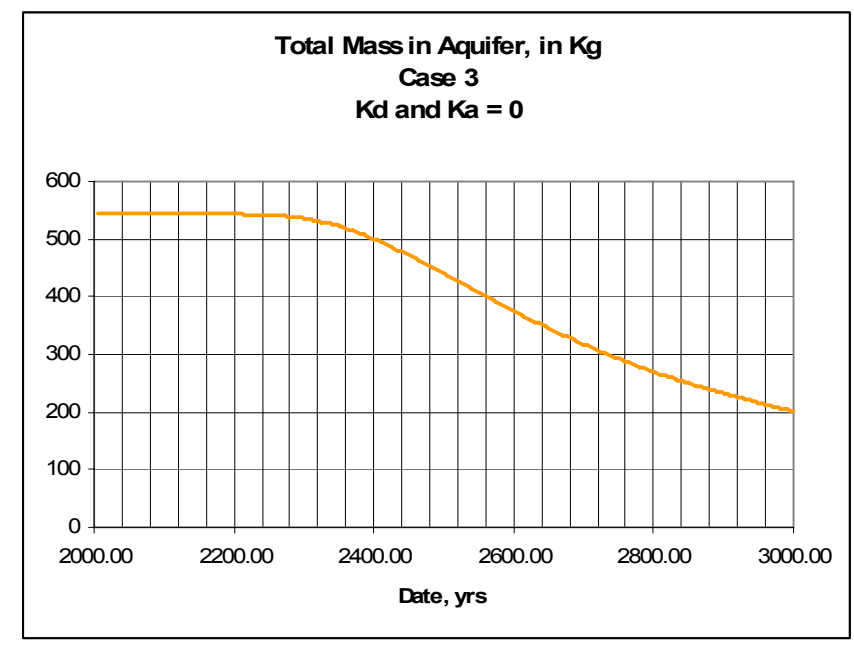

(b)

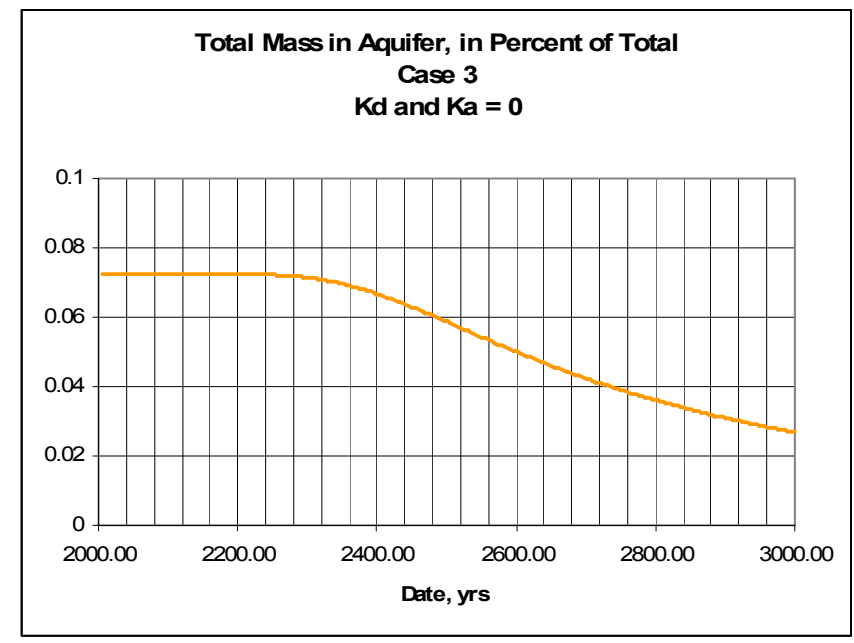

Figure 3.14. Total Mass in Aquifer for Case $3(a=k g ; b=\%$ of total) 


\subsection{Results and Conclusions}

Key results of the modeling analysis are discussed in detail in Section 3 and summarized in Table 4.1 and Figure 4.1. These results of this modeling analysis gave rise to the following conclusions:

- Case 1a, which was based on assumptions of a continuing source with no sorption or abiotic degradation, resulted in:

- Development and migration of a substantial carbon tetrachloride plume from source areas in the 200 West Area to the Columbia River. Predicted concentrations exceeded the benchmark MCL of $5 \mu \mathrm{g} / \mathrm{L}$ reached about $200 \mu \mathrm{g} / \mathrm{L}$ at the arbitrary boundary chosen for this analysis and about $30 \mu \mathrm{g} / \mathrm{L}$ at discharge points along the Columbia River during the 1000 -year period of analysis.

- An equilibrium carbon tetrachloride release estimate of about $73 \mathrm{~kg} / \mathrm{yr}$ in the source area.

- Mass in the aquifer ranged from an initial condition of about $542 \mathrm{~kg}$ at the start of the simulation to about $58,050 \mathrm{~kg}$ in the year 3000 .

- Case $1 b$, which was based on assumptions of median value estimates for sorption and abiotic degradation, resulted in:

- Limited development and migration of a carbon tetrachloride plume from source areas within the general vicinity of the 200 West Area. Predicted concentrations were just below the benchmark MCL of $5 \mu \mathrm{g} / \mathrm{L}$, reaching $4.5 \mu \mathrm{g} / \mathrm{L}$ at the arbitrary boundary chosen for this analysis. Concentrations were well below MCL at the discharge areas along the Columbia River during the 1000-year period of analysis.

Table 4.1. Results of Analyses

\begin{tabular}{|c|c|c|c|c|c|}
\hline \multirow[b]{2}{*}{ Case } & \multicolumn{2}{|c|}{$\begin{array}{l}\text { Max. Concentration in } \mu \mathrm{g} / \mathrm{L} \\
\text { (time of max) }\end{array}$} & \multirow{2}{*}{$\begin{array}{l}\text { Max. aquifer } \\
\text { area above } \\
5 \mu \mathrm{g} / \mathrm{L} \text { in } \mathbf{k m}^{2} \\
\text { (time of max) }\end{array}$} & \multirow{2}{*}{$\begin{array}{l}\text { Loading rate to } \\
\text { aquifer in } \mathrm{kg} / \mathrm{yr} \\
\text { (percent of } \\
\text { estimated total } \\
\text { inventory) }\end{array}$} & \multirow{2}{*}{$\begin{array}{l}\text { Total mass in } \\
\text { aquifer in kg } \\
\text { (percent of } \\
\text { estimated total } \\
\text { inventory) }\end{array}$} \\
\hline & \begin{tabular}{|c|} 
Arbitrary \\
boundary between \\
200 E and W Areas
\end{tabular} & $\begin{array}{c}\text { Columbia } \\
\text { River } \\
\text { boundary }\end{array}$ & & & \\
\hline Case 1a & $200(\mathrm{yr} 3000)$ & $30(\mathrm{yr} 3000)$ & $\begin{array}{c}250 \\
(\mathrm{yr} 3000)\end{array}$ & $\begin{array}{c}73.3 \\
(0.0098)\end{array}$ & $\begin{array}{c}542(0.07)^{(\mathrm{a})} \\
58050(7.8)^{(\mathrm{b})}\end{array}$ \\
\hline Case 1b & $4.5(\mathrm{yr} 3000)$ & $\mathrm{n} / \mathrm{a}^{(\mathrm{c})}$ & $\begin{array}{c}13.6 \\
(\mathrm{yr} 3000)\end{array}$ & $\begin{array}{c}30.9 \\
(0.0041)\end{array}$ & $\begin{array}{c}500(0.07) \\
3372(0.4)^{(b)}\end{array}$ \\
\hline Case 2 & $6.5(\mathrm{yr} 2180)$ & $0.5(\mathrm{yr} 2440)$ & $\begin{array}{c}10.8 \\
(\mathrm{yr} 2200)\end{array}$ & $\mathrm{n} / \mathrm{a}$ & $\begin{array}{l}543(0.07)^{(\mathrm{a})} \\
200(0.03)^{(\mathrm{b})}\end{array}$ \\
\hline Case 3 & $6.5(\mathrm{yr} 2180)$ & $0.5(\mathrm{yr} 2440)$ & $\begin{array}{c}3.7 \\
(\mathrm{yr} 2200)\end{array}$ & $\mathrm{n} / \mathrm{a}$ & $\begin{array}{l}536(0.07)^{(\mathrm{a})} \\
199(0.03)^{(\mathrm{b})}\end{array}$ \\
\hline $\begin{array}{l}\text { (a) Estim } \\
\text { (b) Estim } \\
\text { (c) } \mathrm{n} / \mathrm{a}=\end{array}$ & $\begin{array}{l}\mathrm{d} \text { mass in aquifer at } \\
\mathrm{d} \text { mass in aquifer at } \\
\text { applicable. }\end{array}$ & art of simula & & & \\
\hline
\end{tabular}



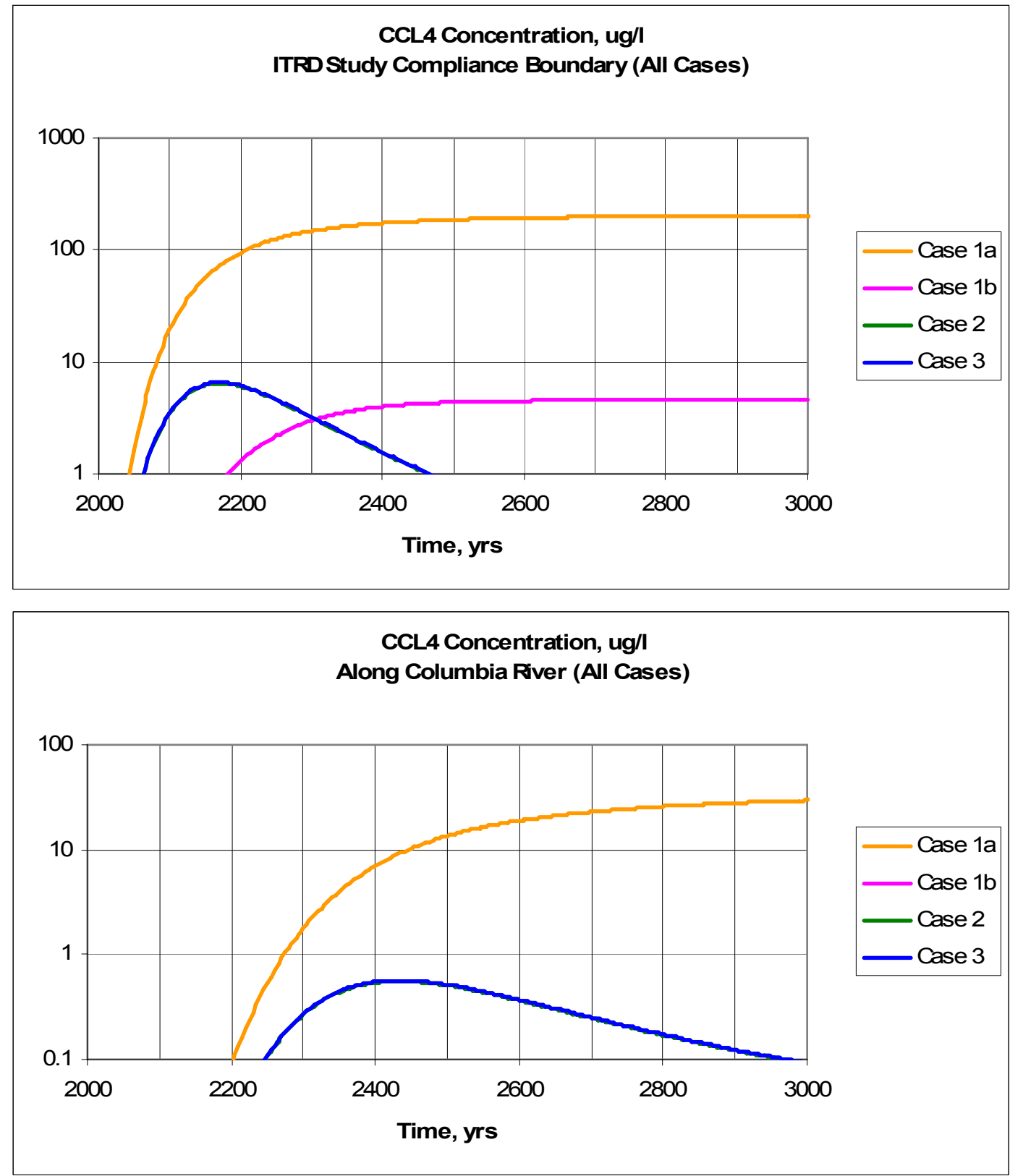

Figure 4.1. Carbon Tetrachloride Concentration for All Cases $(\mu \mathrm{g} / \mathrm{L})$; (a) at ITRD Study Compliance Boundary and (b) Along Columbia River. Plots of results at the ITRD Study Compliance Boundary and along the Columbia River for Cases 2 and 3 are nearly identical and plot on top of one another. Concentration results for Case $1 \mathrm{~b}$ along the Columbia River are well below the levels of interest and below the minimum concentration level in the plot. 
- The combination of sorption and abiotic degradation significantly limits aquifer source loading and aquifer area and volume affected by the migration of the carbon tetrachloride plume.

- Cases 2 and 3 evaluated the combined effects of removal and no removal of sources from the highest concentrations in the plume, and both assumed there was no continuing source of carbon tetrachloride feeding the aquifer. They used conservative estimates (zero) of sorption and abiotic degradation. Results of both of these cases showed:

- A much more limited development and migration of a carbon tetrachloride plume outside 200 West Area toward the Columbia River than predicted under the continuing source assumption evaluated in Case 1a..

- A predicted concentration profile reaching $6.5 \mu \mathrm{g} / \mathrm{L}$ and exceeding the benchmark MCL of $5 \mu \mathrm{g} / \mathrm{L}$ at the arbitrary boundary between 200 East and West Areas over a period of about 600 years between 2100 and 2700. This contrasts with the rapidly rising and plateauing profile of carbon tetrachloride concentrations predicted under the continuing source assumption evaluated in Case 1a.

- Concentrations at discharge areas along the Columbia for these cases were predicted to be well below the benchmark MCL level of $5 \mu \mathrm{g} / \mathrm{L}$ during the 1000-year period of analysis.

- The effect of simulating complete source removal (Case 2, evaluation of estimated initial aquifer concentration levels after concentrations at or above the $3,000 \mu \mathrm{g} / \mathrm{L}$ contour are set to zero) and no source removal (Case 3, evaluating transport of the estimated initial aquifer concentrations) was difficult to distinguish using the metrics established in these analyses (i.e., predicted concentrations at the arbitrary compliance boundary location and along the Columbia River and the total aquifer areas above specified concentration levels).

In summary, the results of these analyses illustrate the importance of developing field-scale estimates of $\mathrm{K}_{\mathrm{d}}$ and especially $\mathrm{K}_{\mathrm{a}}$ appropriate for carbon tetrachloride in the Hanford sediments. With $\mathrm{K}_{\mathrm{d}}$ and $\mathrm{K}_{\mathrm{a}}$ of zero, carbon tetrachloride concentrations will exceed the compliance limit of $5 \mu \mathrm{g} / \mathrm{L}$ outside the 200 Area Plateau WMA, and the aquifer source loading and area of the aquifer affected will continue to grow until river arrival rates equal source release rates. Results of this comparative modeling showed that natural attenuation parameters $\mathrm{K}_{\mathrm{d}}$ and especially $\mathrm{K}_{\mathrm{a}}$ are critical in predicting the future movement of carbon tetrachloride from the 200 West Area. Results also show the significant change in predictions if source release from the vadose zone is assumed to be a continual long-term source of contaminant or if no longterm source release is assumed. 


\subsection{References}

Cole CR, SK Wurstner, MP Bergeron, MD Williams, and PD Thorne. 1997. Three-Dimensional Analysis of Future Groundwater Flow Conditions and Contaminant Plume Transport in the Hanford Site Unconfined Aquifer System: FY 1996 and 1997 Status Report. PNNL-11801, Pacific Northwest National Laboratory, Richland, Washington.

Swanson LC, VJ Rohay, and JM Faurote. 1999. Hydrogeologic Conceptual Model for the Carbon Tetrachloride and Uranium/Technetium Plumes in the 200 West Area: 1994 Through 1999 Update. BHI-01311, Bechtel Hanford, Inc., Richland, Washington.

Truex MJ, CJ Murray, CR Cole, RJ Cameron, MD Johnson, RS Skeen, and CD Johnson. 2001. Assessment of Carbon Tetrachloride Groundwater Transport in Support of the Hanford Carbon Tetrachloride Innovative Technology Demonstration Program. PNNL-13560, Pacific Northwest National Laboratory, Richland, Washington. 


\section{Appendix}

\section{Predicted Distributions of Carbon Tetrachloride Derived from Modeling Studies After Initial ITRD Investigations}




\section{Appendix}

\section{Predicted Distributions of Carbon Tetrachloride Derived from Modeling Studies After Initial ITRD Investigations}

This appendix contains a series of selected time plane plots (Figures A.1 through A.11) to illustrate results of simulation cases used in this modeling study. The three general cases evaluated as part of the follow-on modeling analysis were as follows:

- Case 1 (Continuing Source) involves a run to examine the effects of a continuing source. For this case the same assumptions used in the ITRD modeling are made (i.e., the groundwater system near the source is in equilibrium with the source). As a result, the continuing source can be simulated by holding all of the aquifer volume with concentrations at or above $3,000 \mu \mathrm{g} / \mathrm{L}$ at existing concentration levels until the remaining source inventory has been released $(487,500 \mathrm{~kg} \sim 65 \%$ of the estimated unaccounted-for disposal mass of 750,000 kg). Two variations of this case were investigated. Each involves different assumptions for the controlling transport parameters in order to bound possible outcomes.

- Conservative variation with the natural attenuation parameters set to zero (i.e., $K_{d}=0$ and $\mathrm{K}_{\mathrm{a}}=0$ ), where $\mathrm{K}_{\mathrm{a}}$ is the abiotic degradation rate and $\mathrm{K}_{\mathrm{d}}$ is the soil/water equilibrium sorption coefficient.

- Best-estimate variation using median values for the $\mathrm{K}_{\mathrm{a}}=0.00956 \mathrm{yr}^{-1}$ (reaction halftime $=$ $72.5 \mathrm{yr}$ ) and $\mathrm{K}_{\mathrm{d}}=0.000322 \mathrm{~m}^{3} / \mathrm{kg}$ (retardation factor $=2.6$ ) determined from the Literature Review: Natural Attenuation Mechanisms and Rates for Chloromethane Subsurface Contamination at Hanford provided to the ITRD Technical Advisory Group and included as Appendix C in the ITRD report (Truex et al. 2001).

- Case 2 (Source Removal) simulates the effects of source removal. For this case all of the aquifer volume at or above the $3,000 \mu \mathrm{g} / \mathrm{L}$ contour was set to zero, simulating complete source removal. Thus, only the effects related to continued migration of the plume outside the source area were evaluated. For this case the conservative values for natural attenuation parameters were used $\left(\mathrm{K}_{\mathrm{d}}=0\right.$ \{retardation factor $\left.=1.0\right\}$ and $\mathrm{K}_{\mathrm{a}}=0$ \{no abiotic reactions $\left.\}\right)$.

- Case 3 (No Source and No Removal) simulates the effects of the assumption that the only remaining inventory unaccounted for is in the existing plume. For this run the existing plume provides the initial conditions and only the effects of the plume's migration without further source additions are simulated. Like Case 2, only the conservative variation for natural attenuation parameters was investigated (i.e., $\mathrm{K}_{\mathrm{d}}=0$ and $\mathrm{K}_{\mathrm{a}}=0$ ). 

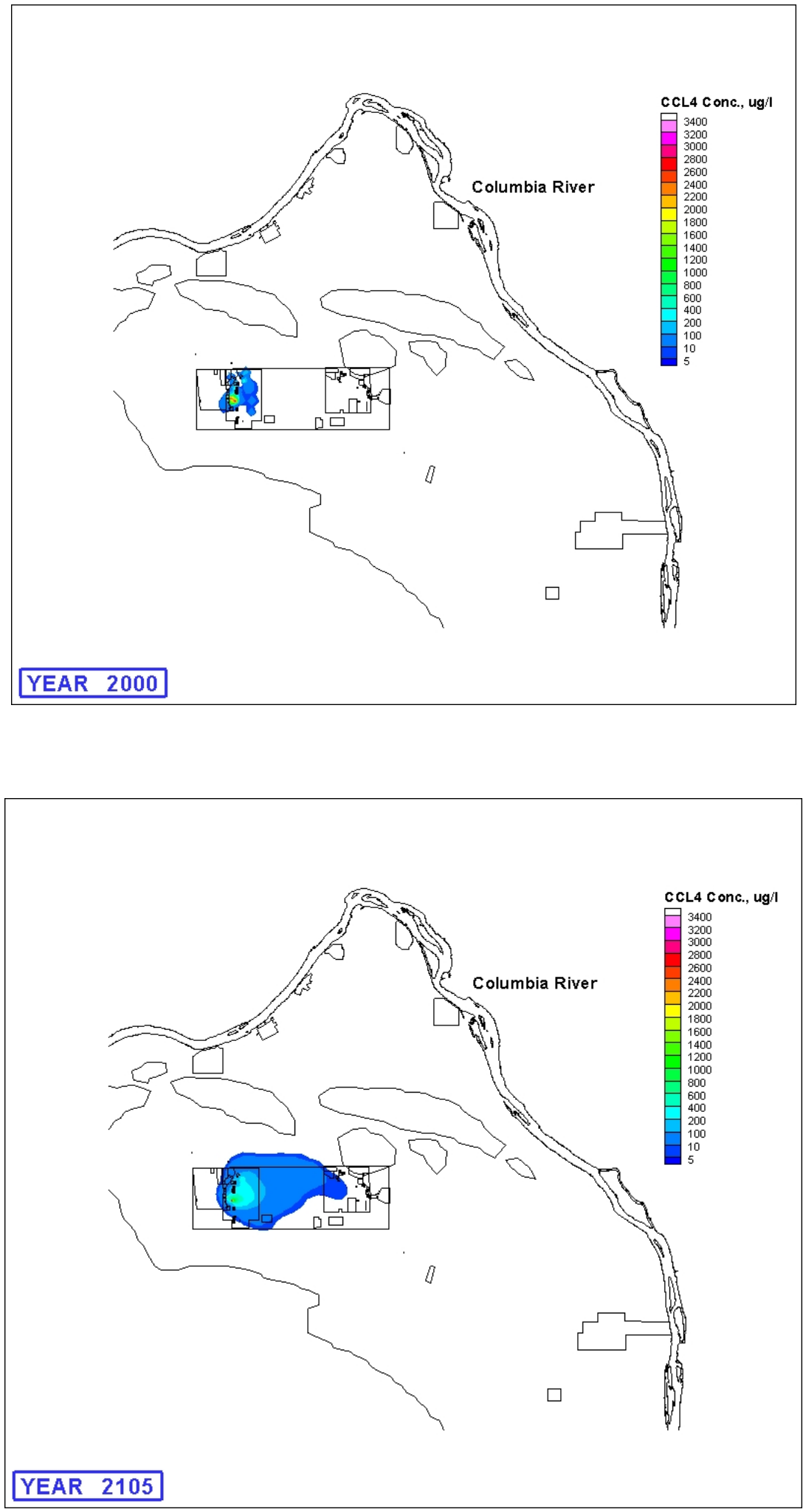

Figure A.1. Case 1a, Continuing Source, $K_{d}$ and $K_{a}=0$ (yr 2000 and 2105) 

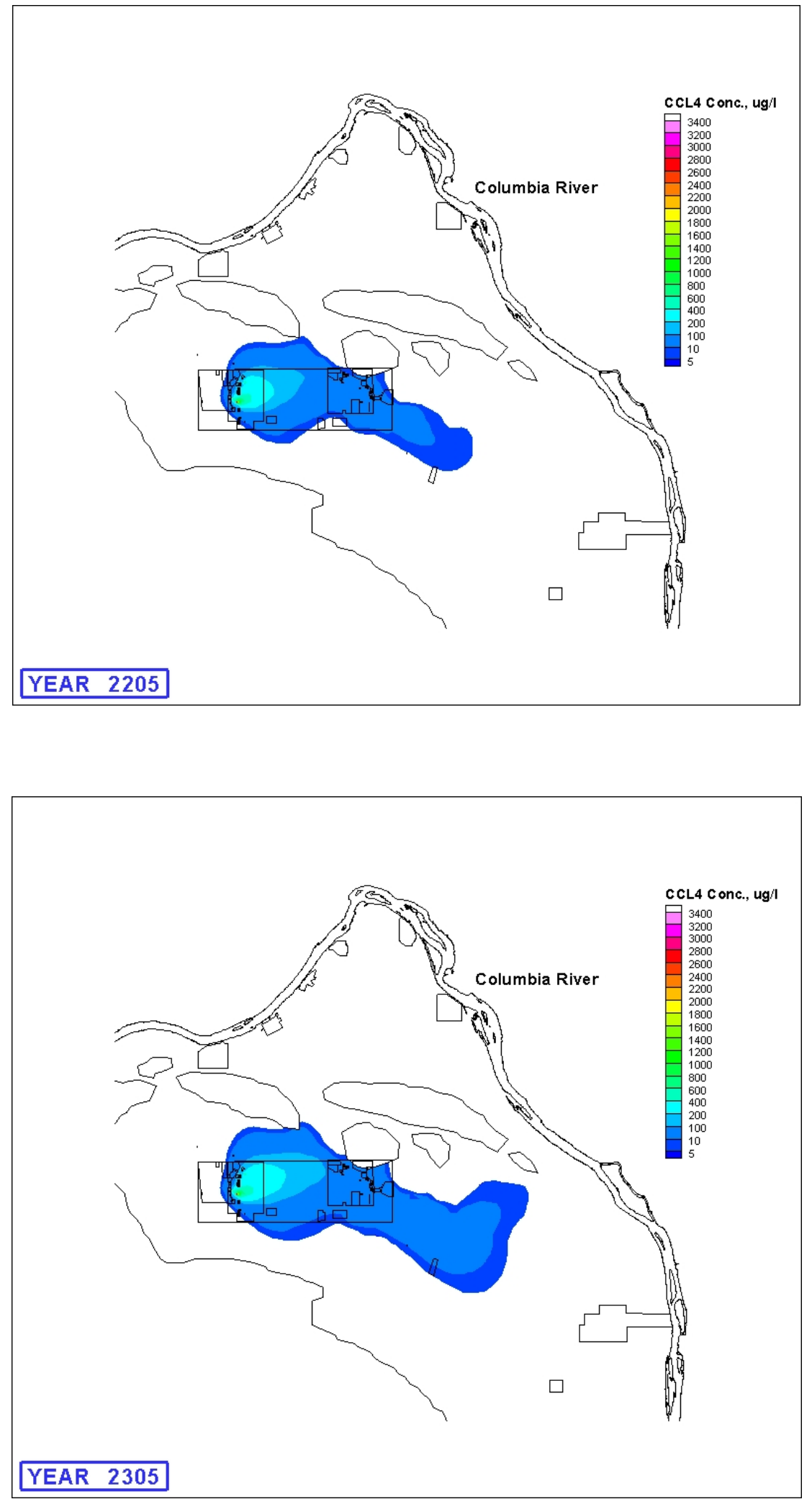

Figure A.2. Case 1a, Continuing Source, $\mathrm{K}_{\mathrm{d}}$ and $\mathrm{K}_{\mathrm{a}}=0$ (yr 2205 and 2305) 

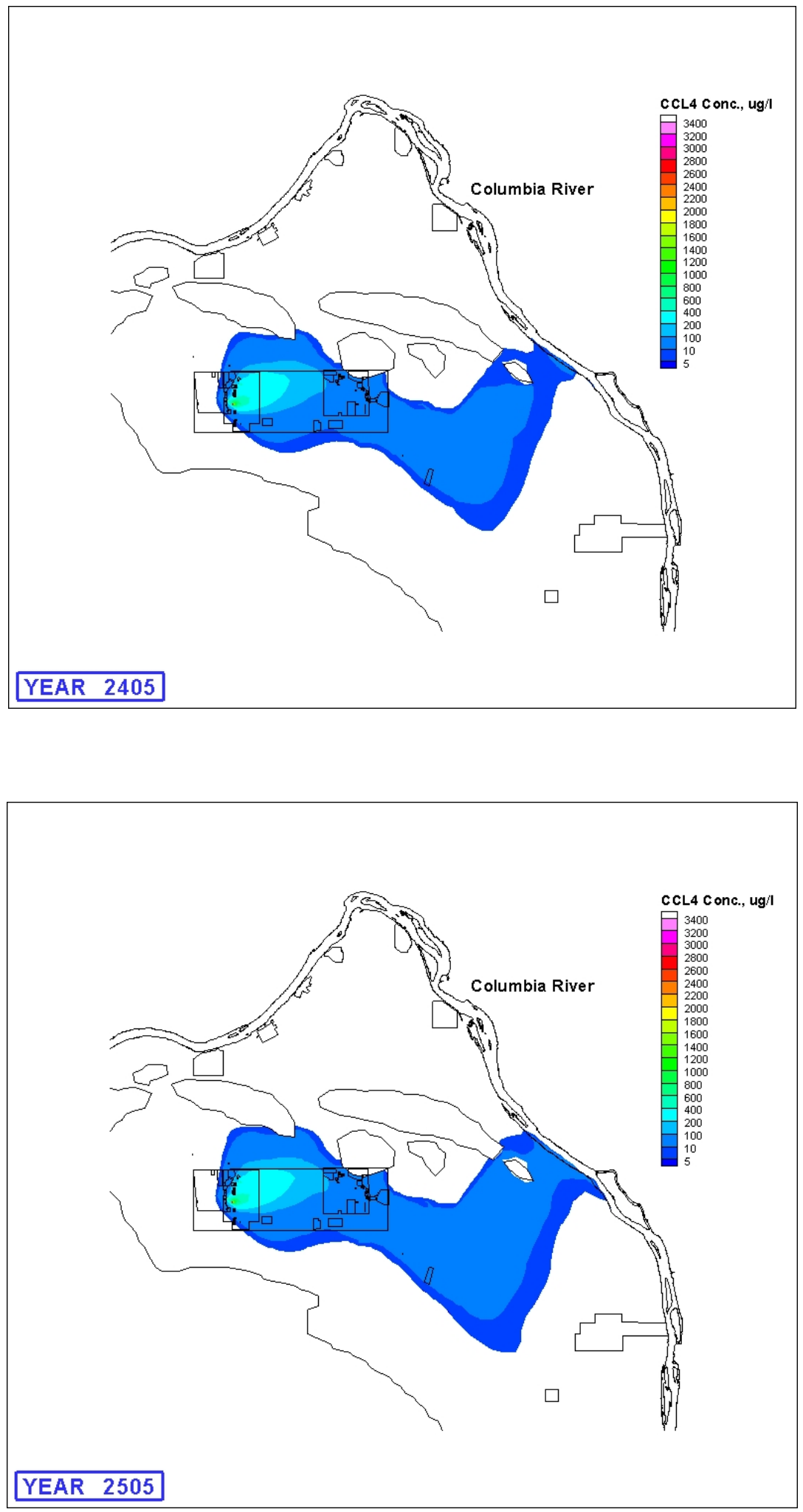

Figure A.3. Case 1a, Continuing Source, $\mathrm{K}_{\mathrm{d}}$ and $\mathrm{K}_{\mathrm{a}}=0$ (yr 2405 and 2505) 

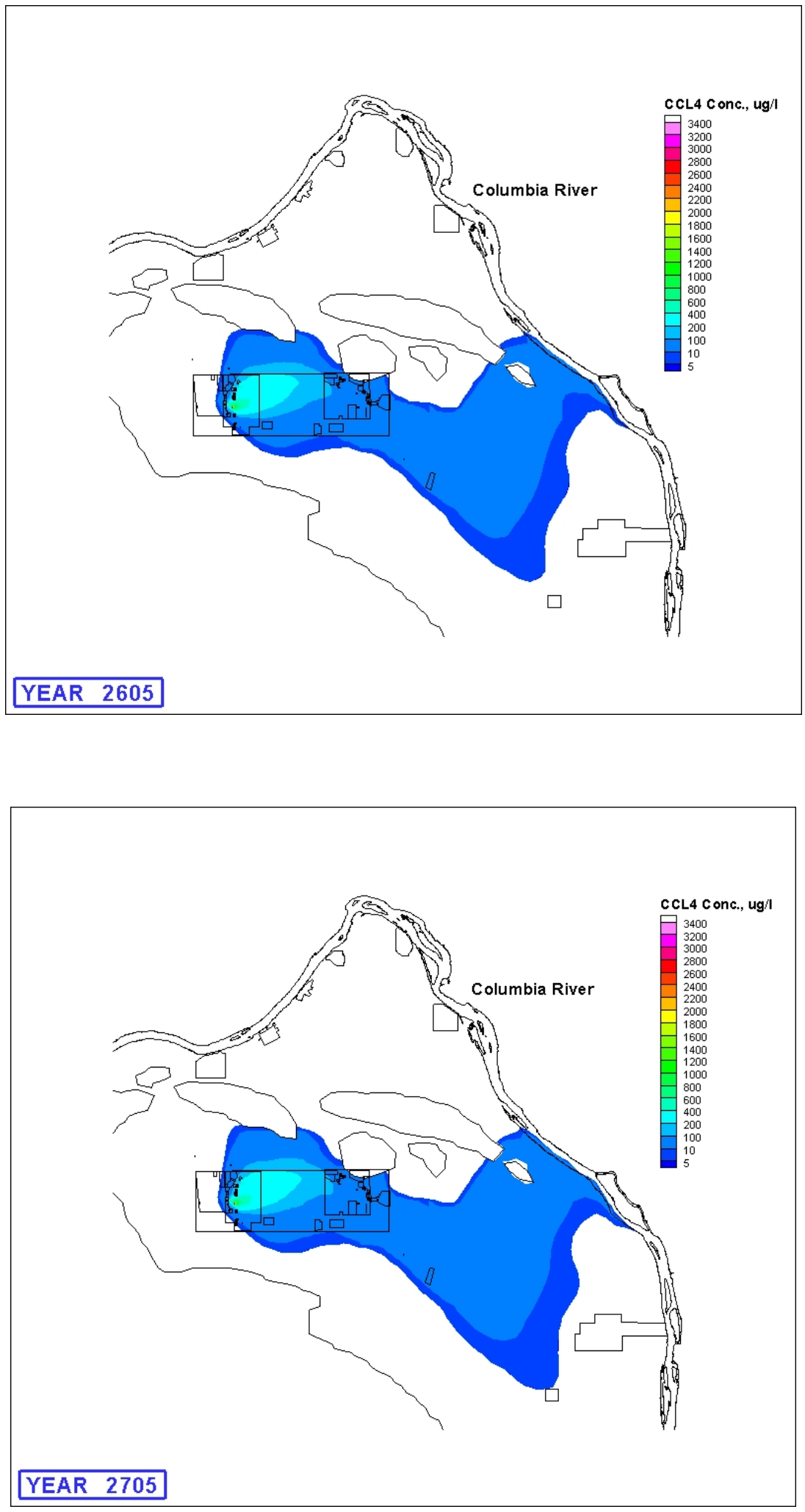

Figure A.4. Case 1a, Continuing Source, $K_{d}$ and $K_{a}=0$ (yr 2605 and 2705) 

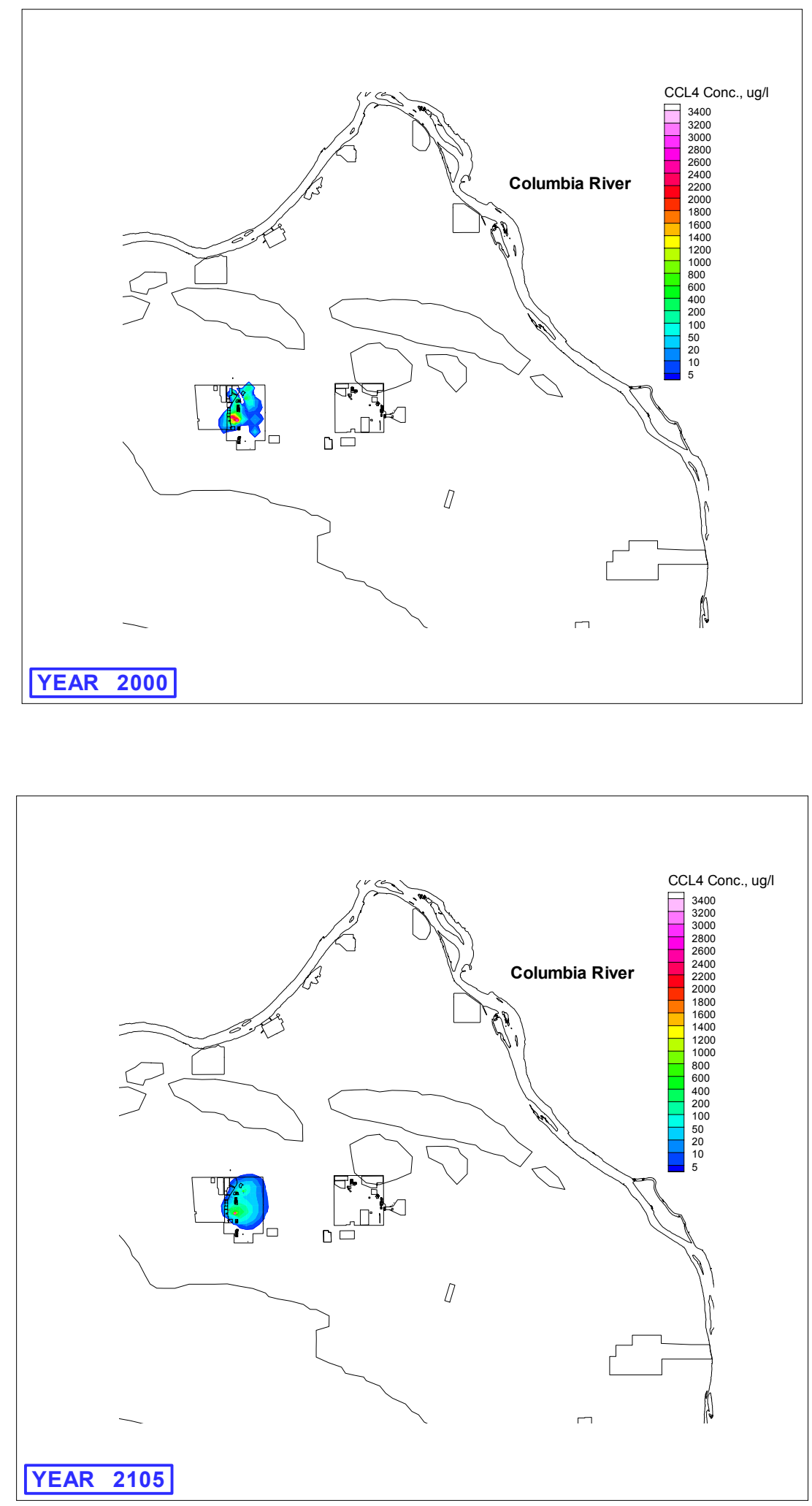

Figure A.5. Case 1b, Continuing Source, Median $\mathrm{K}_{d}$ and $\mathrm{K}_{\mathrm{a}}(\mathrm{yr} 2000$ and 2105) 

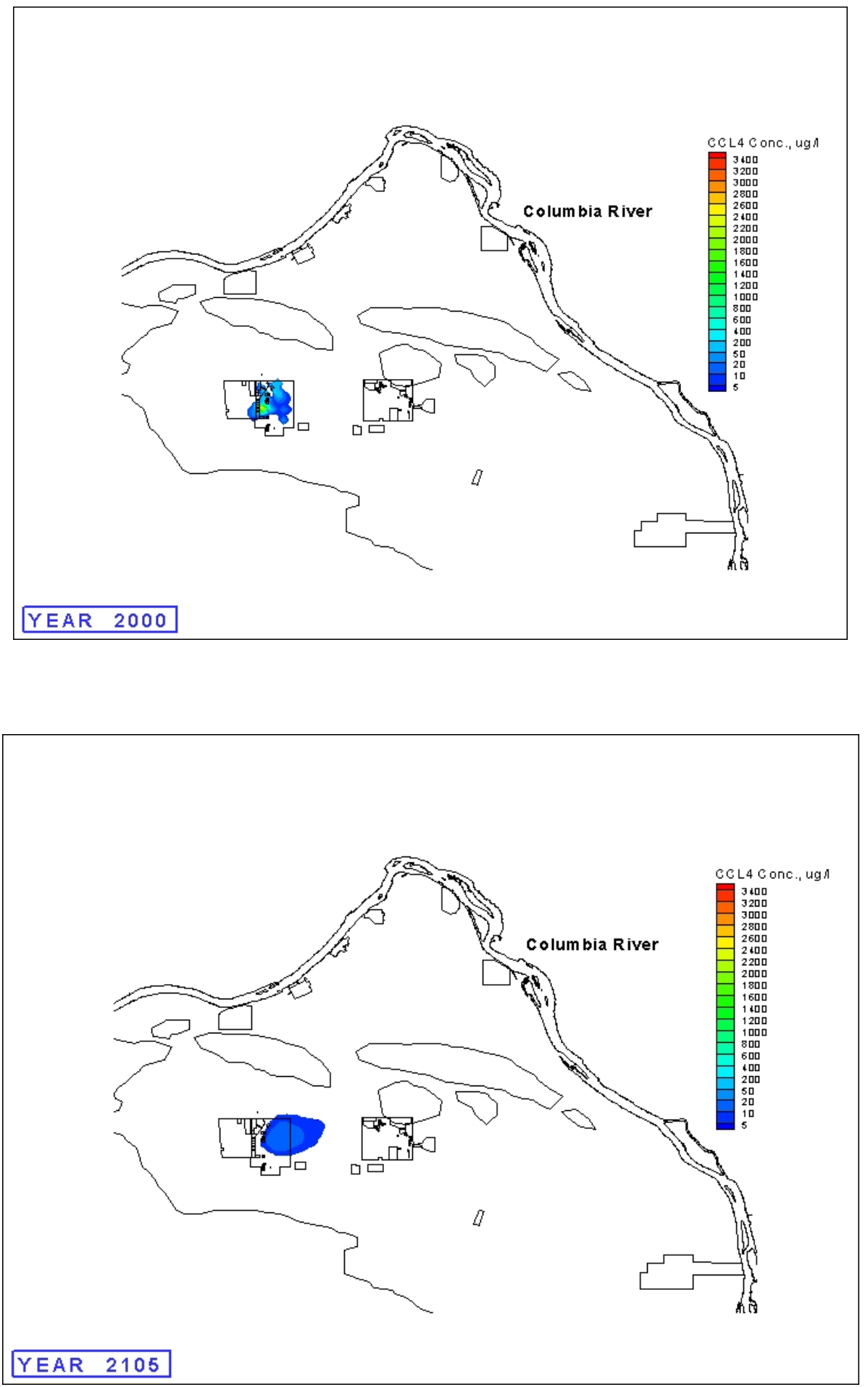

Figure A.6. Case 2, No Continuing Source, Limited Removal of Source Area, $\mathrm{K}_{\mathrm{d}}$ and $\mathrm{K}_{\mathrm{a}}=0$ (yr 2000 and 2105) 

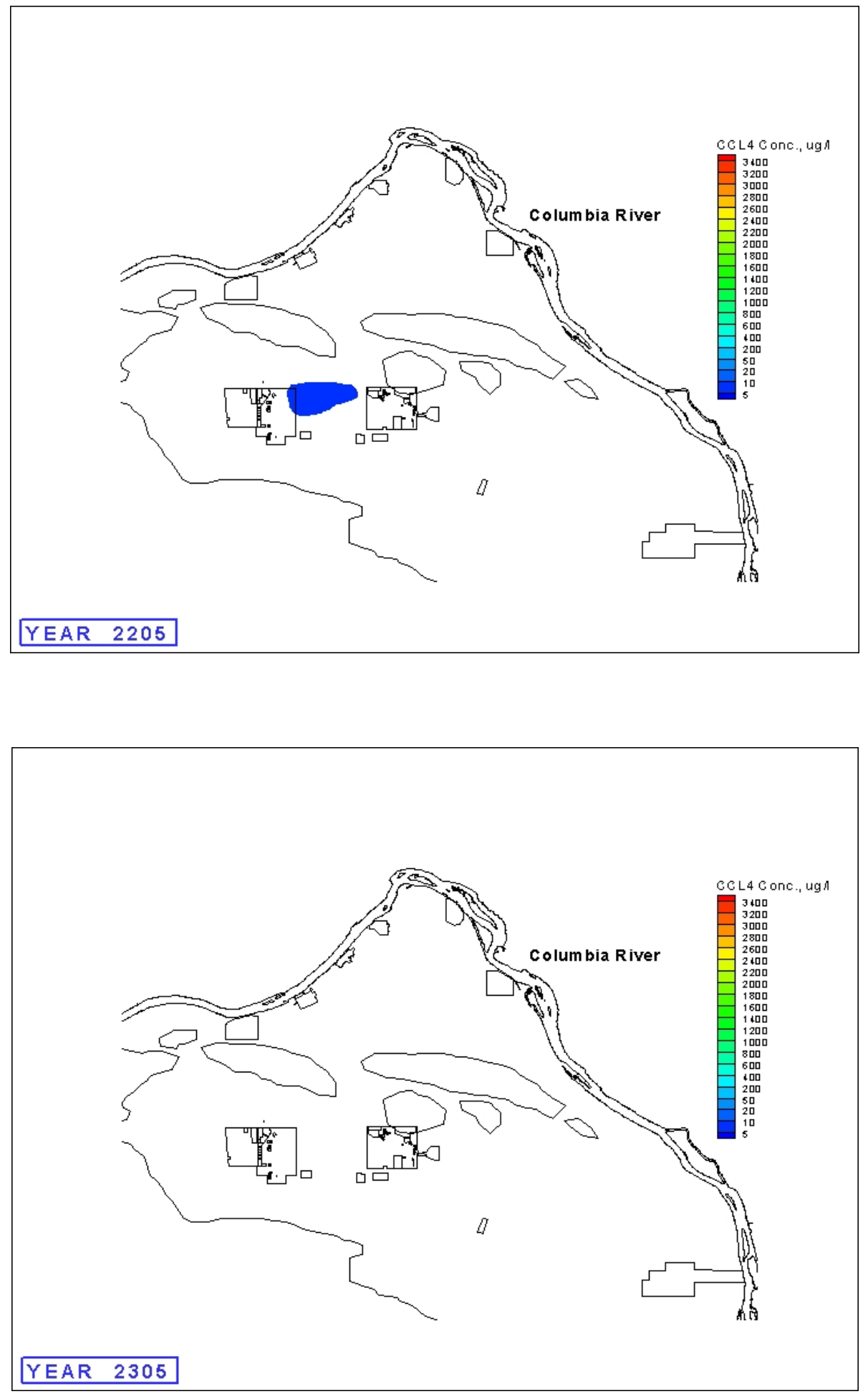

Figure A.7. Case 2, No Continuing Source, Limited Removal of Source Area, $\mathrm{K}_{\mathrm{d}}$ and $\mathrm{K}_{\mathrm{a}}=0$ (yr 2205 and 2305) 

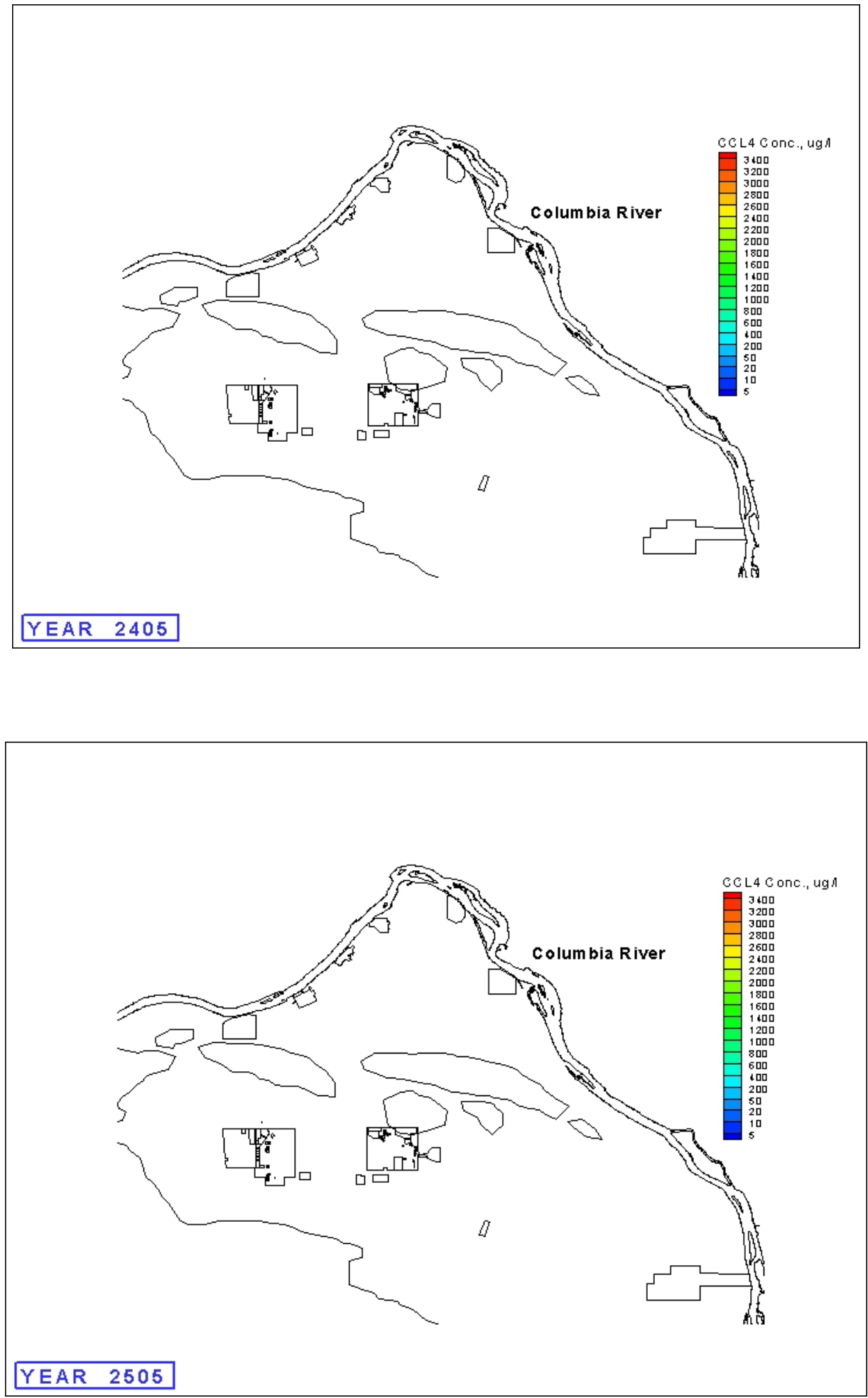

Figure A.8. Case 2, No Continuing Source, Limited Removal of Source Area, $\mathrm{K}_{\mathrm{d}}$ and $\mathrm{K}_{\mathrm{a}}=0$ (yr 2405 and 2505) 

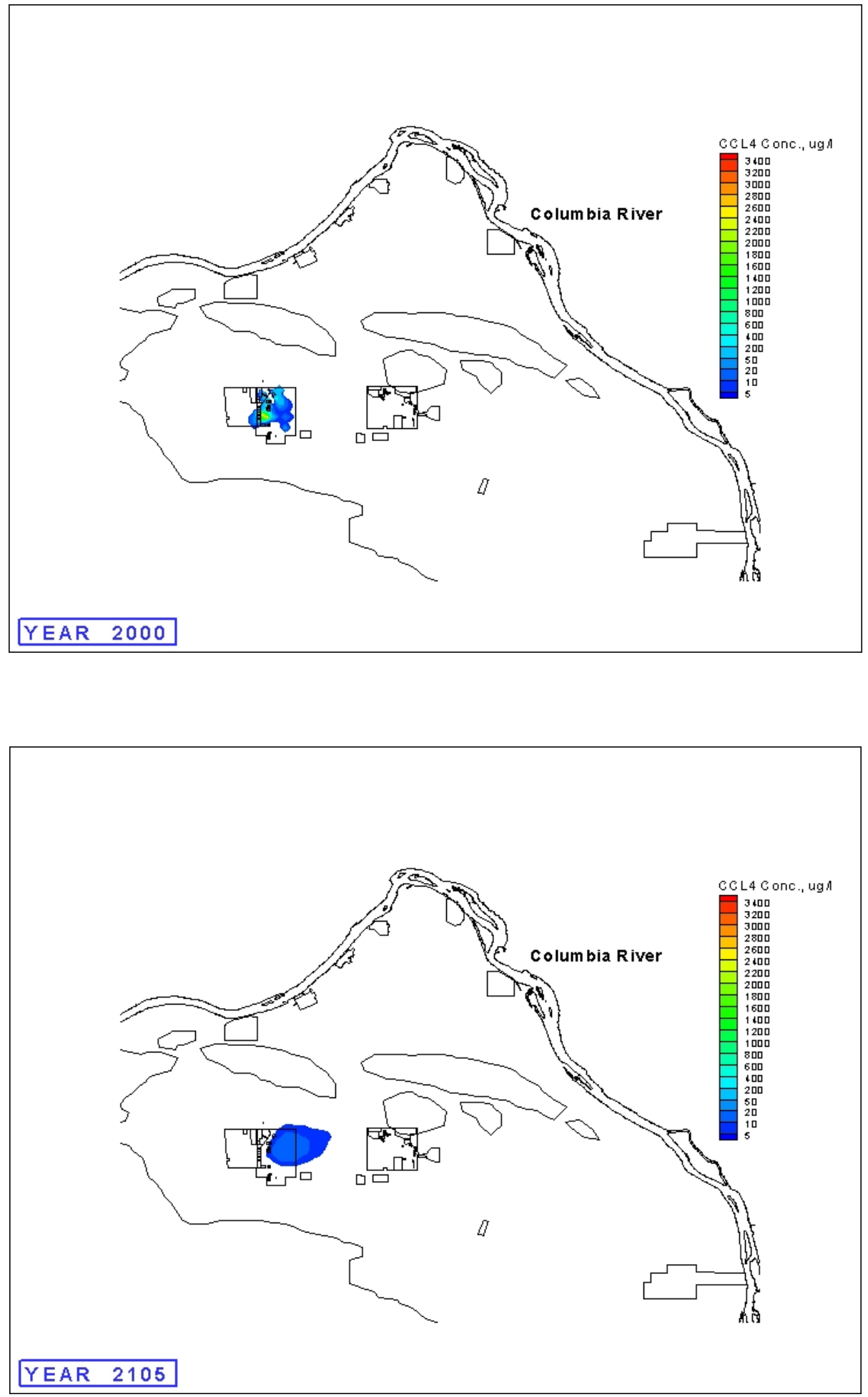

Figure A.9. Case 3, No Continuing Source, No Limited Removal of Source Area, $\mathrm{K}_{\mathrm{d}}$ and $\mathrm{K}_{\mathrm{a}}=0(\mathrm{yr} 2000$ and 2105) 

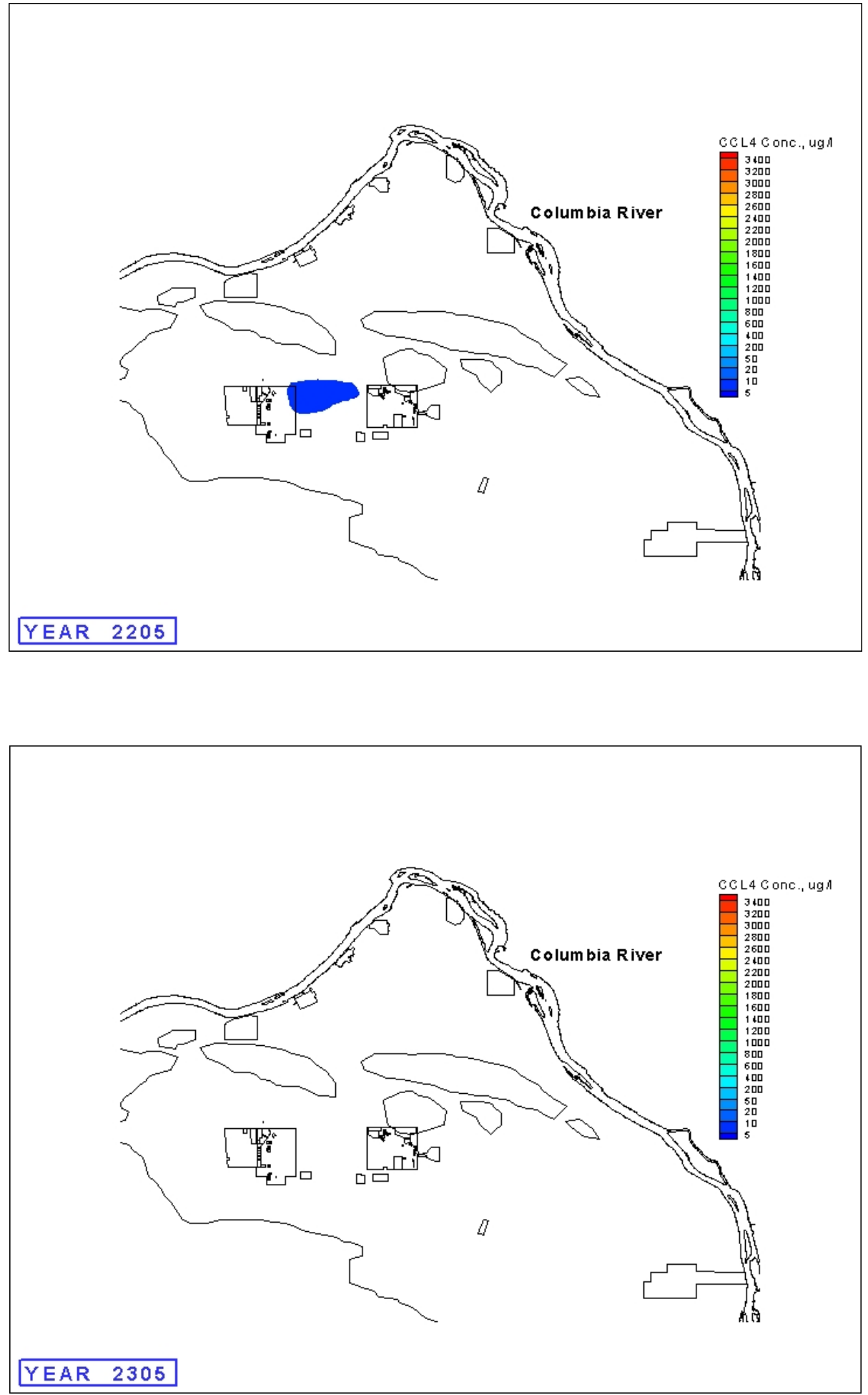

Figure A.10. Case 3, No Continuing Source, No Limited Removal of Source Area, $\mathrm{K}_{\mathrm{d}}$ and $\mathrm{K}_{\mathrm{a}}=0(\mathrm{yr} 2205$ and 2305) 

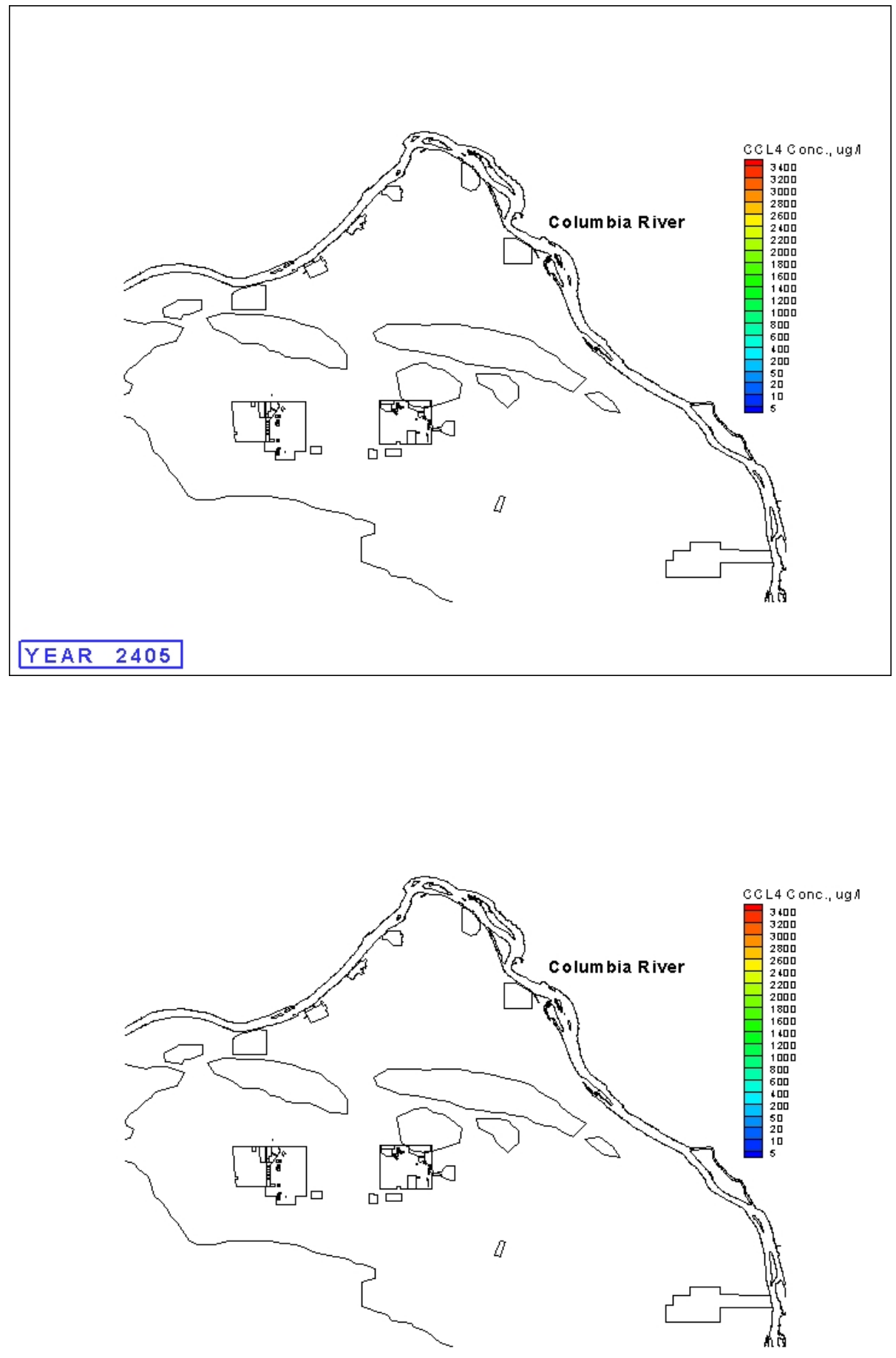

YEAR 2505

Figure A.11. Case 3, No Continuing Source, No Limited Removal of Source Area, $K_{d}$ and $K_{a}=0$ (yr 2405 and 2505) 


\section{Distribution}

No. of

Copies

\section{OFFSITE}

K. Niles

Oregon Department of Energy

625 Marion St. N.E.

Salem, OR 97310

S. Bede

U.S. Ecology

P.O. Box 638

Richland, WA 99352

2 R. Buck, Jr.

Wanapum Indian Band

P.O. Box 878

Ephrata, WA 98823

5 D. N. Goswami

Washington State Dept. Ecology

1315 W. $4^{\text {th }}$

Kennewick, WA 99336-6018

2 Yakima Indian Nation

P.O. Box 151

Toppenish, WA 98948

ATTN: R. Jim

W. Riggsbee

2 S. Harris

Confederated Tribes of the Umatilla

P.O. Box 638

Pendleton, OR 97801

Nez Perce Indian Tribe

P.O. Box 365

Lapwai, ID 83540-0365

ATTN: D. L. Powaukee
No. of

Copies

2 B. W. Drost

U.S. Geological Survey

1201 Pacific Avenue, Suite 600

Tacoma, WA 98402

R. Link

U.S. Bureau of Reclamation

PN-3600

1150 N. Curtis Rd., Suite 100

Boise, ID 83706-1234

K. Didricksen

U.S. Bureau of Reclamation

P.O. Box 620

Grand Coulee, WA 99133

\section{ONSITE}

3 DOE Office of River Protection
R. M. Yasek
H6-60
R. W. Lober
H6-60
S. A. Wiegman
H6-60

13 DOE Richland Operations Office

B. L. Charboneau A6-33

B. L. Foley A6-38

R. D. Hildebrand A6-38

R. G. Morse A6-38

K. M. Thompson A6-38

D. H. Chapin A3-04

K. D. Leary A6-38

Bechtel Hanford Inc.

K. R. Fecht

H9-01 
No. of

Copies

7 CH2M HILL Hanford Group, Inc.

M. P. Connelly

E6-35

F. J. Anderson

E6-35

A. J. Knepp

F. M. Mann

W. J. Mchon

D. A. Myers

C. D. Wittreich

2 Fluor Federal Services
R. Khaleel
R. J. Puigh

8 Fluor Hanford, Inc.

J. V. Borghese

M. E. Byrnes

B. H. Ford

T. W. Fogwell

V. J. Rohay

L. C. Swanson

M. E. Todd-Robertson

M. L. Woods
E6-35

H6-03

E6-35

E6-35

E6-35

H6-62

E6-17

E6-17

E6-35

E6-35

E6-35

E6-35

E6-35

E6-35

H8-44

43 Pacific Northwest National Laboratory

S. Q. Bennett

M. J. Fayer

E. J. Freeman

V. L. Freedman

M. D. Freshley

J. S. Fruchter

G. W. Gee

D. G. Horton

C. T. Kincaid

G. V. Last

S. P. Luttrel

W. J. Martin

C. J. Murray

T. G. Naymik

W. E. Nichols

S. P. Reidel

M. L. Rockhold

F. A. Spane

M. B. Triplett

P. D. Thorne

S. Waichler

A. L. Ward

M. S. Wigmosta

M. D. Williams

S. K. Wurstner

S. B. Yabusaki
K6-50

K9-33

K9-36

K9-36

K9-33

K9-96

K9-33

K6-81

K9-33

K6-81

K6-96

K6-81

K6-81

K6-96

K9-33

K6-81

K9-36

K6-96

K6-52

K9-33

K9-36

K9-33

K9-36

K9-36

K9-36

K9-36
M. P. Bergeron
K9-36
B. N. Bjornstad
K6-81
R. W. Bryce
E6-35
C. R. Cole
K9-36
A. Coleman
K9-33 